\title{
Harnessing Type I IFN Immunity Against SARS-CoV-2 with Early Administration of IFN- $\beta$
}

\author{
Donald C. Vinh ${ }^{1} \cdot$ Laurent Abel ${ }^{2,3,4} \cdot$ Paul Bastard $^{2,3,4} \cdot$ Matthew P. Cheng ${ }^{1} \cdot$ Antonio Condino-Neto $^{5}$. \\ Peter K. Gregersen ${ }^{6}$. Filomeen Haerynck ${ }^{7}$. Maria-Pia Cicalese ${ }^{8}$. David Hagin ${ }^{9}$ • Pere Soler-Palacín ${ }^{10}$. \\ Anna M. Planas ${ }^{11}$ - Aurora Pujol ${ }^{12,13}$ • Luigi D. Notarangelo ${ }^{14}$. Qian Zhang ${ }^{2}$. Helen C. Su ${ }^{14}$. \\ Jean-Laurent Casanova ${ }^{2,3,4,15} \cdot$ Isabelle Meyts ${ }^{16,17}$ (D) . On behalf of the COVID Human Genetic Effort
}

Received: 26 March 2021 / Accepted: 17 May 2021 / Published online: 8 June 2021

(C) The Author(s), under exclusive licence to Springer Science+Business Media, LLC, part of Springer Nature 2021

\section{Introduction}

Since December 2019, over 150 million individuals have been infected with SARS-CoV-2 globally. While most cases $(>95 \%)$ are asymptomatic or mild, a small proportion develop moderate, severe, or critical COVID-19 pneumonia requiring hospitalization, at times in the intensive care unit [1]. At least 2 million patients have already died [2]. The main epidemiological risk factor associated with critical pneumonia or death is age $>65$ years; however, life-threatening COVID-19 has also affected younger people, albeit sporadically. Studies have suggested that type I interferon (IFN) immunity contributes to the control of SARS-CoV-2 infection [3-8]. Notably, inborn

Isabelle Meyts

isabelle.meyts@uzleuven.be

1 McGill University Health Centre, Montreal, Canada

2 St Giles Laboratory of Human Genetics of Infectious Diseases, Rockefeller Branch, Rockefeller University, New York, NY 10065, USA

3 Laboratory of Human Genetics of Infectious Diseases, Necker Branch, INSERM UMR 1163, Necker Hospital for Sick Children, 75015 Paris, France

4 University of Paris, Imagine Institute, 75015 Paris, France

5 University of São Paulo, São Paulo, Brazil

6 Feinstein Institute for Medical Research, Northwell Health USA, Manhasset, NY, USA

7 Department of Paediatric Immunology and Pulmonology, Centre for Primary Immunodeficiency Ghent (CPIG), PID Research Lab, Jeffrey Modell Diagnosis and Research Centre, Ghent University Hospital, Ghent University, Ghent, Belgium

8 Pediatric Immunohematology and Bone Marrow Transplantation Unit, San Raffaele Telethon Institute for Gene Therapy (SR-Tiget), IRCCS San Raffaele Scientific Institute, Milan, Italy errors of TLR3- and IRF7-dependent type I IFN production or amplification underlie severe disease in $\sim 3 \%$ of a cohort of relatively young adult patients analyzed by the COVID Human Genetic Effort (COVIDhge.com) [3]. In at least an additional $10 \%$ of cases, high levels of pre-existing auto-antibodies (auto-Abs) neutralizing most type I IFNs, but rarely IFN- $\beta$, abrogate type I IFN-dependent control of SARS$\mathrm{CoV}-2$ replication in vitro, thereby underlying critical disease in vivo $[3,4,9,10]$. This observation was replicated in other cohorts [11-15]. The mean age of patients with inborn errors was 48 years, while that of patients with auto-Abs was 65 years. These findings support a two-step model of COVID19 pathogenesis: defective type I IFN immunity in the first

9 Allergy and Clinical Immunology Unit, Department of Medicine, Tel Aviv Sourasky Medical Center and Sackler Faculty of Medicine, Tel Aviv, Israel

10 Pediatric Infectious Diseases and Immunodeficiencies Unit, Hospital Universitari Vall d'Hebron, Vall d'Hebron Research Institute, Vall d'Hebron Barcelona Hospital Campus, Universitat Autònoma de Barcelona (UAB), Barcelona, Catalonia, Spain

11 IIBB-CSIC, IDIBAPS, Barcelona, Catalonia, Spain

12 Neurometabolic Diseases Laboratory, IDIBELL-Hospital Duran I Reynals; Catalan Institution for Research and Advanced Studies (ICREA), Barcelona, Catalonia, Spain

13 CIBERER U759, ISCiii, Madrid, Spain

14 Laboratory of Clinical Immunology and Microbiology, National Institutes of Health, Bethesda, MD, USA

15 Howard Hughes Medical Institute, New York, NY, USA

16 Department of Pediatrics, University Hospitals Leuven, Leuven, Belgium

17 Laboratory for Inborn Errors of Immunity, KU Leuven, Leuven, Belgium 
hours and days of infection leads to uncontrolled viral replication with spread to the lungs and other tissues, with subsequent excessive leukocyte recruitment, underlying uncontrolled inflammation [5]. This model of early deficient type I IFN function provides a framework for novel preventive and therapeutic approaches of COVID-19. Here, we explore two therapeutic routes that aim to restore protective type I IFN immunity: [1] the early administration of IFN- $\beta$ in ambulatory subjects, including exposed individuals prior to infection, presymptomatic infected individuals and symptomatic individuals, and [2] the removal of auto-Abs to type I IFN in hospitalized patients. We also discuss the implications of these findings for other preventive and therapeutic interventions, including B cell depletion, JAK inhibitors, intravenous immunoglobulins, the use of convalescent plasma and virus-specific $\mathrm{mAbs}$, and vaccination. This discussion is timely, as more than one year into the pandemic, we are still in the dark about the best prevention and treatment for severe COVID-19 pneumonia, while the emergence of more contagious viral variants, causing more severe disease, raises concerns regarding the efficacy of the nascent vaccination programs $[16,17]$.

\section{Vaccines for COVID-19: Where Do We Stand?}

Currently, several COVID-19 vaccines are in use, and numerous others are in different phases of development. Despite their excellent efficacy and safety profile, the finding that sera from vaccinated individuals showed reduced in vitro neutralization of 5 of 10 pseudoviruses representing circulating SARS-CoV-2 strains is concerning [18]. Moreover, protection from vaccines may wane and not all people will be able to tolerate the vaccines or mount protective responses. For instance, a word of caution is needed for the use of mRNA vaccines in patients with interferonopathies (i.e., autoinflammatory conditions due to excessive type I IFN activity), as these vaccines may potentially induce exaggerated type I IFN responses, despite the introduction of pseudouridine instead of uridine to reduce recognition by nucleic acid sensors. Overall, surveillance studies documenting both safety and efficacy are critically needed in patients with inborn errors of immunity and their phenocopies. Germane to the COVIDhge findings of deficient type I IFN activity in severe COVID-19, more specific questions arise. First, is vaccine efficiency maintained in patients with a genetic or auto-immune phenocopy of type I IFN defect? Indeed, type I IFN has been described to enhance antibody responses and isotype switching by effects on dendritic cells [19]. Do the current vaccines induce sufficient adaptive immunity to compensate for a patient's innate defect in type I IFN or for the pre-existing anti-type I IFN auto-Abs? Is the clinical effectiveness of the vaccines comparable between those with genetic defects of type I IFN response pathway and those with auto-
Abs versus the general population? Although reports from patients with genetic type I IFN defects have not raised concerns about impaired vaccine responses, longitudinal data will be required to more definitively address these questions [20, 21]. The COVIDhge data also open new considerations on safety. As some type I IFN pathway defects, especially autosomal recessive (AR) deficiency of STAT2, IFNAR1, and IFNAR2, predispose to severe disease with live attenuated vaccine (LAV), and as anti-type I IFN auto-Abs can underlie disease caused by the yellow fever vaccine, special caution will be needed with SARS-CoV-2 vaccine strategies that use LAV [22]. We must also recognize that, as SARS-CoV-2 variants with potential to escape vaccine coverage emerge, it is possible that individuals with monogenic or auto- $\mathrm{Ab}$ mediated impairment of type I IFN responses continue to remain at risk for severe disease, despite vaccination. The corollary would propose that individuals who develop COVID19 disease following vaccination, and perhaps those who are repeatedly re-infected as well, may harbor known or novel inborn errors of immunity.

\section{Convalescent Plasma and mAbs}

Convalescent plasma (CP) from recovered patients is being administered in severe and critical COVID-19, prompted by historical experience with SARS-CoV, MERS-CoV, and 1918 Spanish flu [23, 24]. The rationale is that passive immunization against SARS-CoV-2 can ameliorate disease by decreasing virus spread and replication. It is expected to be beneficial mainly in the initial phases of disease. Risks of $\mathrm{CP}$ therapy include those of standard plasma infusions; for instance, volume overload and transfusion-related acute lung injury require special care $[23,25]$. A theoretical risk is antibody-dependent enhancement, in which non-neutralizing antibodies against SARS-CoV-2 worsen disease by engaging Fc receptors which modulate effector functions of monocytes/ macrophages and mediate cytokine release [26]. Eight randomized clinical trials (RCTs) using CP have been reported and most failed to show a beneficial effect on clinical status or mortality, conflicting with the observational studies [27-29]. Subsequently, an additional double-blind placebo-controlled clinical trial showed no efficacy in improving morbidity/ mortality in patients with severe COVID-19 when administered at a median of 8 days after symptom onset, whereas another double-blind placebo-controlled clinical trial showed decreased disease progression in mildly affected patients when administered within $72 \mathrm{~h}$ after symptom onset [30, 31]. There are over 100 ongoing studies evaluating CP. These studies need to teach us [1] the minimum levels of anti-SARS-CoV-2 neutralizing antibodies needed to prevent or abort development of severe disease; [2] the optimal timing of plasma collection from donors after disease resolution; and 
[3] the optimal dosing and timing of infusions relative to symptom onset in recipients $[32,33]$.

In the context of the findings of the COVIDhge, the main concern is that $\mathrm{CP}$, if harvested from severely ill or hospitalized COVID-19 patients, may contain neutralizing type I IFN auto-Abs [15]. In that case, CP therapy could worsen disease in the recipient. Thus, CP should only be collected from asymptomatic or mildly ill COVID-19 patients and must be tested for neutralizing auto-Abs against type I IFN, even though at present, the threshold of auto-Abs that leads to critical COVID-19 has yet to be defined. Of note, the general application of such strategy is only possible when and where a standardized, validated assay to detect neutralizing anti-type I IFN auto-Abs is readily available with a quick turnaround time ( $<24 \mathrm{~h})$. Recombinant monoclonal antibodies, targeted against SARS-CoV-2 spike protein, obviate these concerns and are potentially safer [34-36]. Moreover, the neutralizing titers achieved with for instance REGN-COV2 (a cocktail of casirivimab plus imdevimab, two non-competing neutralizing human IgG1 antibodies targeting the receptor binding domain of the spike protein) were more than 1000 times the titers achievable with CP. A combination of bamlanivimab and etesevimab (two other non-competing anti-spike neutralizing monoclonal antibodies derived from 2 patients who recovered from COVID-19), but not bamlanivimab alone, administered within $72 \mathrm{~h}$ of onset, reduced viral load and resulted in a decreased hospitalization rate compared with placebo in mild-to-moderate COVID-19 [36]. REGN-COV2 had a profound and rapid effect on viral load, with most reduction occurring within $48 \mathrm{~h}$ and with a stronger effect in individuals with a high viral load [35]. Studies of the impact on clinical outcome as a primary outcome are ongoing. However, viral strains carrying mutations in the target epitopes of SARSCoV-2 spike protein have already been described, clouding the future of monoclonal antibody treatment [37].

\section{Anti-inflammatory Drugs: Intravenous Immunoglobulin (IVIG), Corticosteroids, and Anti-IL6R Antagonists}

In the two-step model of critical COVID-19, the first phase of insufficient type I IFN immunity results in deleterious pulmonary and systemic inflammation, calling for anti-inflammatory interventions. High-dose IVIG $(0.8 \mathrm{~g} / \mathrm{kg}$ to $2 \mathrm{~g} / \mathrm{kg})$ has immunomodulatory capacity, presumably via inhibition of complement system activation; decreased endothelial cell activation; anti-inflammatory effects on monocytes, macrophages, and neutrophils; and stimulation of regulatory T cells [38]. Highdose IVIG has been used in several studies in COVID-19 as an immunomodulatory therapy to treat multisystem inflammatory syndrome in children and adults associated with SARSCoV-2 infection, but also in severe COVID-19 pneumonia
[39-45]. A retrospective multicenter study conducted in China reported reduced mortality at day 28 in critically ill COVID-19 patients treated with high-dose IVIG [46]. Two RCTs with high-dose IVIG were recently published. The first study compared $1.2 \mathrm{~g} / \mathrm{kg}$ IVIG plus hydroxychloroquine and lopinavir/ritonavir to the latter treatment alone, and its results did not support the use of IVIG [47]. A smaller study, with 30 patients in each treatment arm, showed a decreased mortality in patients with severe COVID-19 treated with IVIG [48]. More RCTs are needed to define efficacy, dosing, and timing of high-dose IVIG treatment. In light of COVIDhge findings, administration of high-dose IVIG might have the additional benefit of "washing out" the pathogenic anti-type I IFN autoAbs [49]. High-dose IVIG are thus beneficial in immune thrombocytopenia [50] and Guillain-Barré syndrome [51]. Careful studies of the kinetics of anti-IFN-auto-Abs are necessary, together with longitudinal assessment of serum cytokines, to provide proof of principle for this approach.

Seven RCTs have examined the effect of low-dose steroids, as a broad-acting anti-inflammatory agent, in critical COVID-19, and one RCT in non-critical COVID-19. The largest trial, in 2104 subjects, showed a reduced 28-day mortality (22.9\% vs. $25.7 \%)$ in dexamethasone versus usual care [52]. A meta-analysis of all trials showed a significant decrease in day 28 mortality for dexamethasone compared to supportive care in three trials, in patients with critical COVID-19 [53]. A more specific approach to dampen the cytokine storm in COVID-19 is by targeting IL-6, using the anti-IL6 receptor (IL6R) blocking monoclonal antibodies, tocilizumab, or sarilumab. Multiple observational studies hinted towards improved outcome using tocilizumab. Several RCTs have now been conducted in severe COVID19 [54-60]. The largest trial, which focused on patients with critical COVID-19, reported reduced days on organ support and a small reduction mortality in patients receiving anti-IL6R antagonists versus placebo (27\% in the pooled tocilizumab or sarilumab arm vs. $36 \%$ in the placebo arm, REMAP-CAP trial) [61]. Overall, the RCTs have been unimpressive in terms of beneficial effect on survival [62].

\section{Anti-inflammatory Agents that Interfere with Type I IFNs: JAK Inhibitors}

Several classes of drugs interfere with the type I IFN pathways, including antagonists/monoclonal antibodies targeting IFNAR/IFN. Janus kinase (JAK) inhibitors (Jakinibs) target many signaling pathways, depending on their selectivity [63]. Ruxolitinib inhibits JAK1 and JAK2 and thereby interferes with, respectively, the common cytokine receptor $\gamma$-chain (used by IL-2, IL-4, IL-7, IL-9, IL-15); the gp130 pathway (IL-6, IL-11, OSM, LIF); the class II cytokine receptor family (IFN- $\alpha / \beta$, IFN- $\gamma$, IL-10) (JAK1); and the EPO, TPO, IFN $\gamma$, 
and $\beta \mathrm{c}$ family (IL-3, IL-5, GM-CSF) (JAK2). Tofacitinib potently inhibits JAK3 next to JAK1 and thus may also impair the $\gamma \mathrm{c}$ receptor family. Ruxolitinib is an especially potent inhibitor of type I IFN signaling. Finally, IFN-kinoid (IFN- $\alpha$ coupled to the carrier protein, keyhole limpet hemocyanin) induces the production of antibodies against all 13 IFN $\alpha$ [64]. These drugs are in various phases of development and clinical trials and some have been approved by the FDA to treat malignancies, rheumatoid arthritis, psoriasis, inflammatory bowel disease, and systemic lupus erythematosus.

In the two-phase model of severe COVID-19, use of a Jakinib after the initial phase could dampen inflammatory cascades triggered by ligand-binding to the multiple cytokine receptors as described above. However, in the early phase, when type I IFN signaling is crucial for antiviral defense, the biological consequences of Jakinibs and IFN-kinoid resemble the phenotypes of patients with auto-Abs against type I IFNs [4] and AR IFNAR1 or IFNAR2 deficiency [3]. Thus, patients who are already receiving these agents, and become infected with SARS-CoV-2, are potentially at risk for severe COVID19. Thus, it is prudent to consider halting of these drugs in the initial phase of SARS-CoV-2 infection. However, in a retrospective study, of three patients with Aicardi-Goutières syndrome on Jakinibs, 2 were asymptomatically infected and 1 only experienced a rash upon infection [65], although their excessive type I IFN signaling may be incompletely downregulated by the Jakinibs [65]. Additionally, Jakinibs have been or are being studied to treat patients with severe COVID-19 (e.g., ARDS; "cytokine release syndrome"). The ACTT-2 study demonstrated that the Jakinib baricitinib (in association with the antiviral remdesivir) reduced recovery time and accelerated improvement in clinical status in moderate-to-severe COVID-19 [66]. Remdesivir itself failed to show any beneficial effect on initiation of ventilation, duration of hospital stay, and mortality in the recent Interim WHO Solidarity Trial Report $[16,67]$. One additional RCT using ruxolitinib versus placebo in hospitalized patients has recently been completed and 20 more are recruiting [68]. The finding of beneficial effects of Jakinibs in the second phase of moderate-to-severe COVID-19 disease is consistent with the two-stage disease model of COVID-19. However, as the threshold level of type I IFN activity and the duration of type I IFN activity required to mitigate COVID-19 are unknown, caution is required when using IFN-kinoid or Jakinibs.

\section{B Cell and Plasmablast Depletion and BTK Inhibition: How About COVID?}

Depletion of B cells can be achieved with an anti-CD20 antibody (e.g., rituximab). In mycobacterial infections due to antiIFN- $\gamma$ auto-antibodies, another phenocopy of an inborn error of immunity, rituximab has been used with success [69-73].
Depletion of plasmablasts can be achieved by antibodies targeting CD38 (e.g., daratumumab); the latter has been successfully used to treat multiple myeloma [74], autoimmune cytopenias [75], autoimmune organ diseases [76, 77], and infection due to auto-Abs to cytokines [78]. These depletive therapies have not been studied as acute treatment for COVID-19 in the context of RCT or, to our knowledge, even published as case reports. However, results of retrospective studies on the outcome of COVID-19 are inconclusive in patients previously on a B cell-depleting agent for underlying immune-mediated diseases, such as rheumatoid arthritis [79-83]. In the context of COVIDhge, B cell/plasmablast depletion can potentially be used to curb the ongoing secretion of neutralizing anti-type I IFN IgG. Of note, data from patients with X-linked agammaglobulinemia (XLA), which is caused by mutations in Bruton's tyrosine kinase (BTK), suggest they are not untowardly susceptible to severe COVID-19 [65, 84, 85]. This may suggest that absent development of protective neutralizing antibodies to COVID-19, as well as vaccination responses, may not predispose to severe COVID-19 [86]. An alternative or additional explanation may relate to reduced inflammatory cytokine release by BTK-deficient monocytes. In line with this are the promising results seen with the BTK inhibitors, acalabrutinib and ibrutinib, in patients infected with SARS-CoV-2 while on these drugs, and in an observational trial using acalabrutinib in hospitalized patients with severe COVID-19 [87, 88], in which the benefit correlated with the impairment of monocyte activation. Several clinical trials are under way to evaluate the potential benefit of BTK inhibitors in COVID-19. Whether such treatment is associated with persistent shedding of viable SARS-CoV-2 virus is unclear [89-92]. The question of prolonged shedding and temporary blunting of antibody responses will need to be studied when evaluating the use of $\mathrm{B}$ cell/plasmablast depletion during the management of COVID-19 in patients with auto-Abs. These patients may be at risk of re-infection and will not likely be able to respond to vaccines while the B cell deficiency persists.

\section{Therapeutic Plasma Exchange (TPE): Past and Present}

TPE refers to the removal of a large volume of plasma, typically $30-40 \mathrm{ml} / \mathrm{kg}$, necessitating replacement of fluid by a colloid solution (e.g., albumin and/or plasma) or a combination of crystalloid/colloid solution. In contrast, plasmapheresis (PP) is based on removing (not replacing) only $15 \%$ of plasma volume. TPE is currently used in over 60 medical conditions according to the American Society for Apheresis [93]. The rationale of TPE lies in the removal of a pathogenic substance from plasma, such as immune complexes, cryoglobulins, toxins, or lipids. More specifically, TPE has been used 
successfully in conditions mediated by auto-antibodies, such as vasculitis, Guillain-Barré syndrome, Goodpasture syndrome, thrombotic thrombocytopenic purpura, and autoimmune hemolytic anemia, some of which are associated with viral infections [93]. TPE has also been applied in patients with shock-like presentation in the context of respiratory viral infection in an attempt to clear inflammatory and antifibrinolytic mediators of the cytokine storm, and to replenish anticoagulant proteins and to reduce viremia [94-97]. The latter report of TPE in three critically ill children with H1N1 influenza-related acute respiratory distress syndrome showed that TPE is effective even in the later stages of cytokine storm. Importantly, TPE comes at the cost of eliminating protective antibodies and drugs, an issue to consider when managing infection by TPE.

As the risk of developing severe and even potentially fatal COVID-19 pneumonia is extremely high in patients harboring auto-Abs against type I IFN, eliminating these auto-Abs by TPE emerges as an attractive additional line of treatment in hospitalized patients. So far, the use of TPE for COVID-19 pneumonia has been limited to case series. Another case reported the successful use of TPE in a pregnant woman suffering from thrombotic thrombocytopenic purpura with SARS-CoV-2 [98-105]. In these reports from the initial phases of the pandemic, TPE was used empirically for management of the "cytokine storm" during the phase of critical illness [98, 99, 101-104, 106, 107]. In some patients, intravenous immunoglobulins or convalescent plasma from other patients was used to replace circulating antibodies. Although these cases provide anecdotal evidence of potential benefits in some patients with severe COVID-19, they have also raised concern about its general use as a "rescue therapy" for all such patients [108-110]. A prospective clinical trial is required to better define its use [111]. Interestingly, in one of the original reports where TPE was used, the authors demonstrate a reduction in circulating antiphospholipid antibodies [103]. In light of the findings from COVIDhge [4], TPE can be considered specifically in those with demonstrable auto-Abs to type I IFN. Proof of concept for this mechanism-based use of TPE in severe COVID-19 has been recently reported [112]. Interestingly, the depletion of anti-IFN-abs by TPE was not accompanied by a depletion of anti-SARS-CoV-2 IgG [112]. Given the constellation of reports to date, the optimal use of TPE in COVID19 needs to be better defined, including number of sessions needed and choice of volume replacement, but it appears to be best aimed at hospitalized patients with moderate-to-severe/critical disease who harbor anti-type I IFN auto-Abs. As stated above, the feasibility of this approach is contingent on the availability of a certified assay to detect and quantify neutralizing auto-Abs to type I IFN.

\section{Type I IFN: Almost 50 Years of Therapy with IFN- $\alpha$ and IFN- $\beta$ in Various Diseases}

Type I IFN production, amplification, and response contribute to antiviral innate and intrinsic immunity. The first clinically successful use of type I IFN in humans dates back to 1973 and pertained to viral respiratory infections [113]. Type I IFNs were thereafter proposed as treatment of several other viral infections, especially chronic hepatitis $\mathrm{C}(\mathrm{HCV})$ and hepatitis $B$ (HBV) virus infections. Recombinant IFN- $\alpha 2$ was first used in HCV treatment in 1986 [114]. Pegylated IFN- $\alpha 2$ (PEGIFN- $\alpha 2$ ), allowing sustained blood levels, was introduced in the early 2000s and became standard treatment for chronic $\mathrm{HCV}$ infection until the appearance of direct-acting antivirals [115]. At present, PEG-IFN- $\alpha 2$ is still a treatment option in mild-to-moderate chronic hepatitis B patients. IFN- $\alpha 2 \mathrm{a}$ and IFN- $\alpha 2 b$ are also used as an adjuvant in cancer treatment, such as certain leukemias (e.g., hairy cell; chronic myeloid) and Kaposi's sarcoma [116], based on its anti-proliferative, anti-angiogenesis, and immunomodulatory actions. Recombinant IFN- $\beta 1 \mathrm{a}$ and IFN- $\beta 1 \mathrm{~b}$, which exert effects similar to those of IFN- $\alpha 2$, have also been used therapeutically. IFN- $\beta 1$ a is a standard treatment for relapsing-remitting multiple sclerosis (MS) since the 1990s [117-119]. Short-term IFN- $\alpha 2$ treatment is associated in $20-30 \%$ with self-limiting flu-like symptoms. Long-term IFN- $\alpha 2$ treatment is associated with various side effects including (\% affected; onset) fever (20-30\%; 4-6 h after injection; self-limited); asthenia (6090\%; 3 months); psychiatric manifestations with depression and suicidal ideation (5-60\%; 3 months); and thyroid autoimmunity (3-6\%; median 17 weeks) [120-122]. Adverse reactions to IFN- $\beta$ are similar to those of IFN- $\alpha$ [118]. In addition, long-term treatment with either molecule may illicit neutralizing anti-drug antibodies that can adversely affect treatment, as first reported in a patient receiving IFN- $\beta$ for nasopharyngeal carcinoma [123-126]. These idiosyncratic reactions may be polygenically driven [127]. In all, short-term IFN- $\alpha$ or IFN- $\beta$ treatment appears safe with little side effects and has proven efficient in the treatment of certain viral infections.

\section{IFN-a2 in Past and Current COVID Trials}

In the context of COVID-19, a NIH-issued guideline advises to restrict the use of IFN to clinical trials. Understandably, based on type I IFN's direct inhibitory effects on viral replication and indirect immunomodulatory effects, and based on its antiviral experience, IFN- $\alpha$ was one of the first drugs to be repurposed during the ongoing pandemic [128]. Only a few studies, and no randomized double-blind placebo-controlled trials (DBRCT), using IFN- $\alpha 2$ as a treatment have been published (Table 1). In a retrospective study, 242 of 446 hospitalized patients with severe COVID-19 received aerosolized 


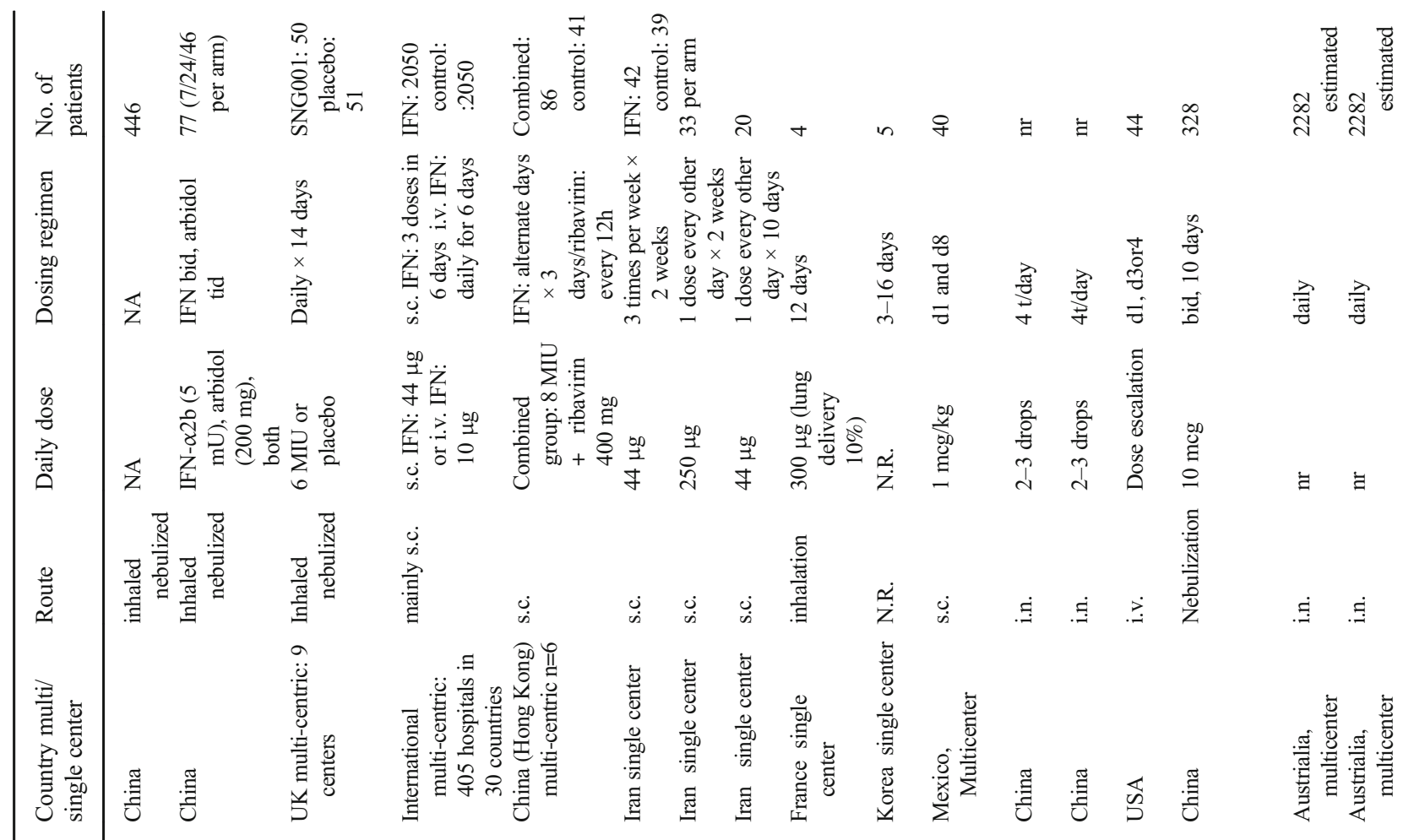

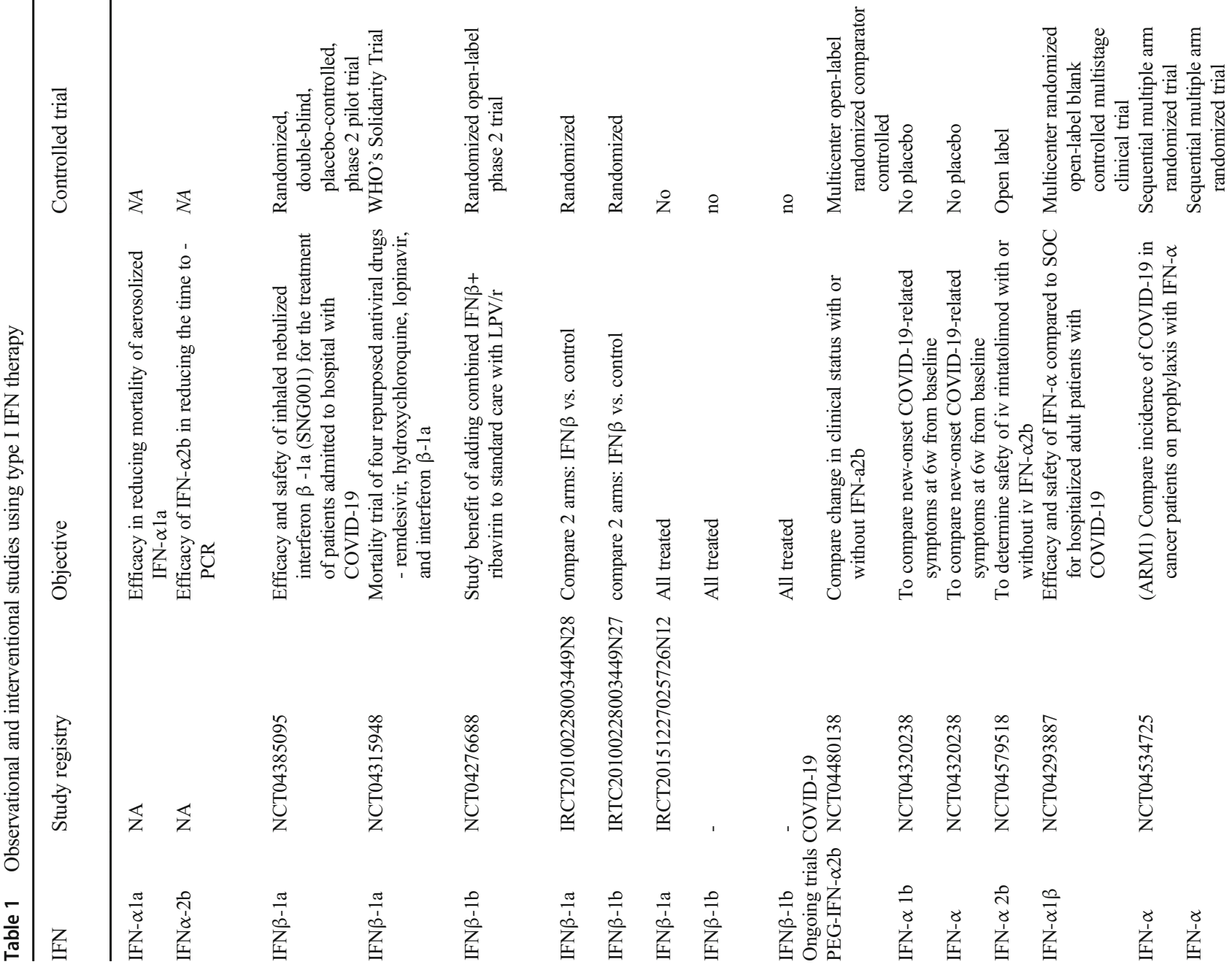




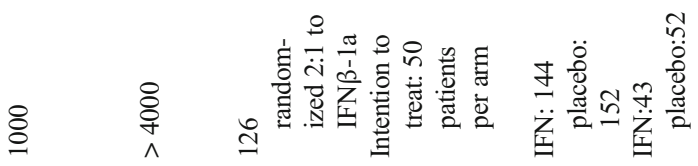

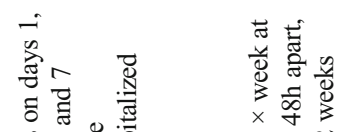

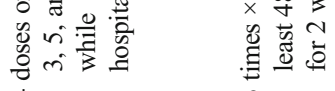

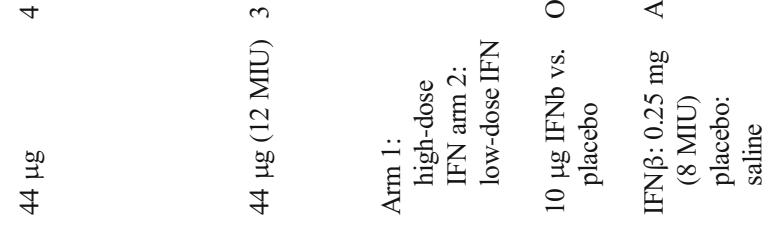

ن் $\dot{\text { i }}$

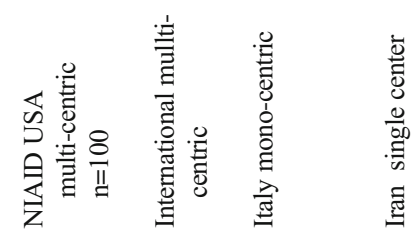

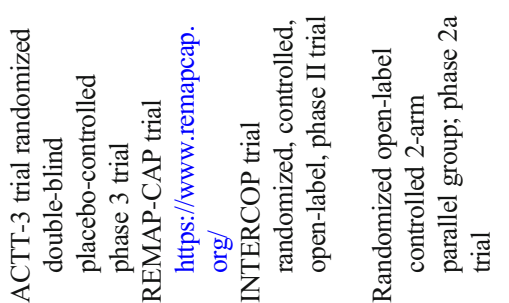

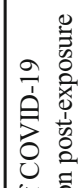

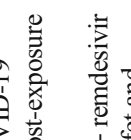

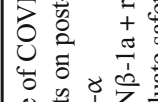

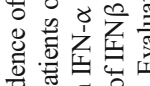

远

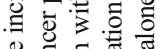

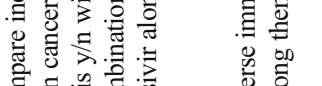

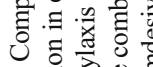

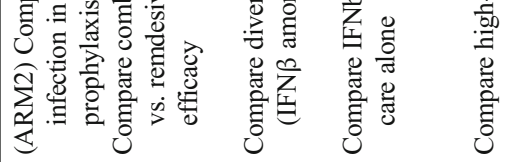

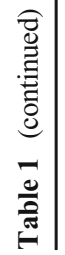

$\stackrel{\dot{s}}{\dot{s}}$

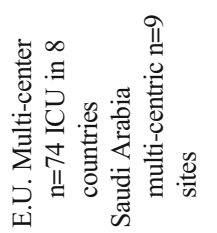

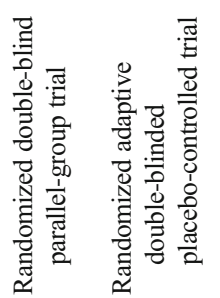

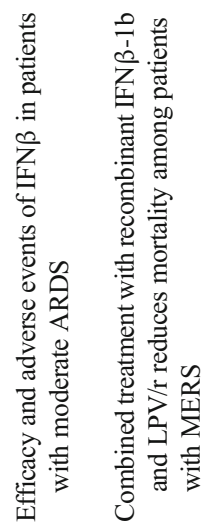

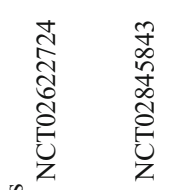

䓀 吕

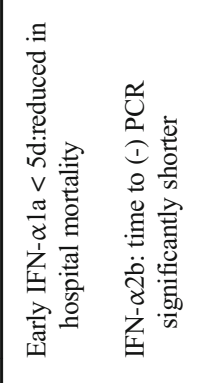

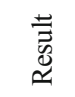

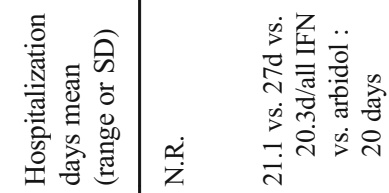

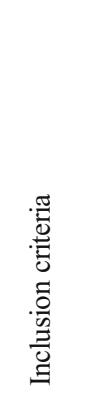

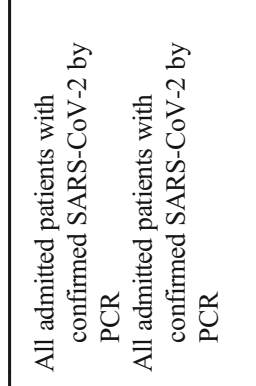

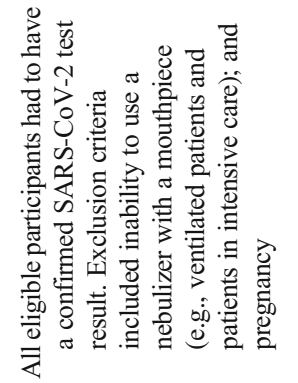

$\bar{\Xi}$

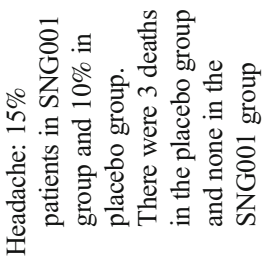

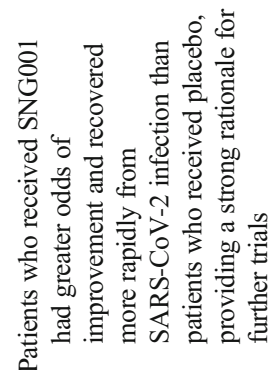

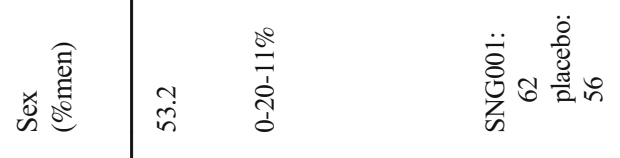



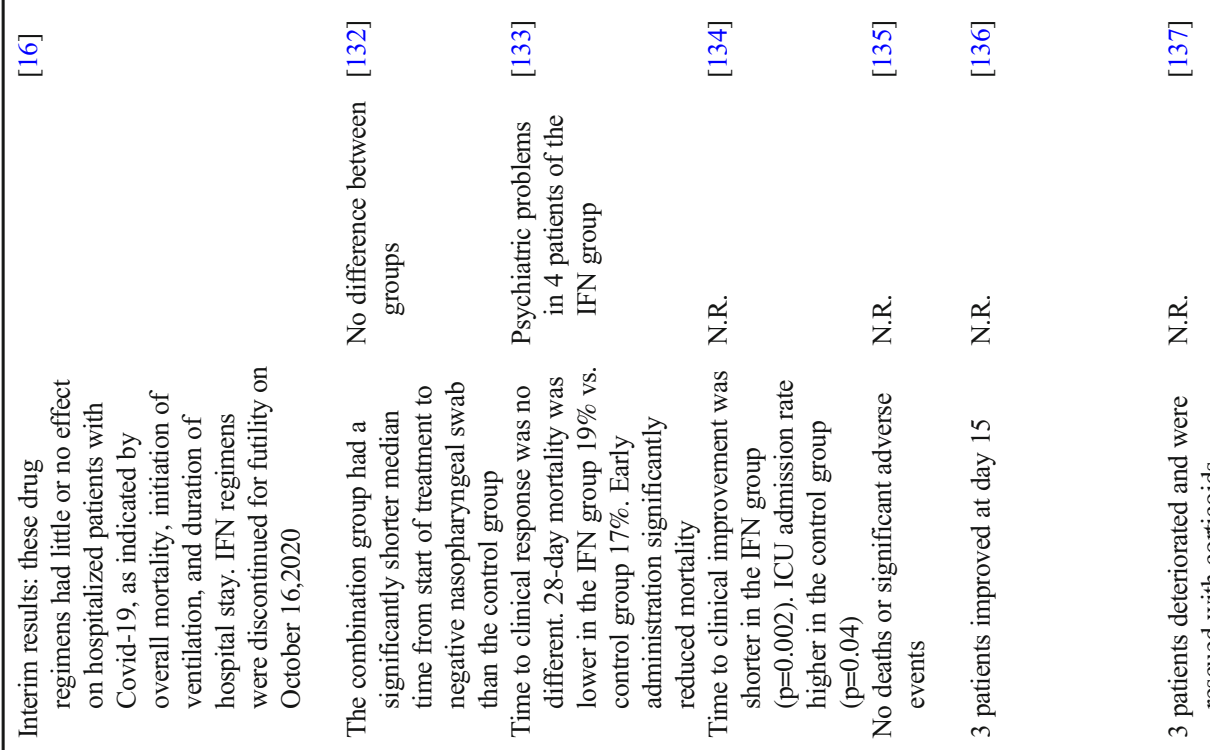

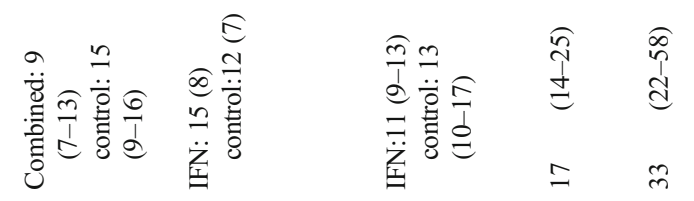

$\sqrt{2}$

$\stackrel{\check{z}}{\mathrm{z}}$

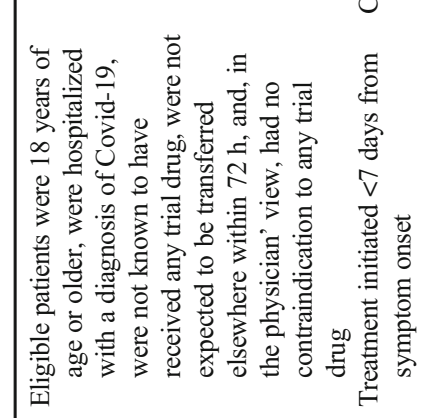

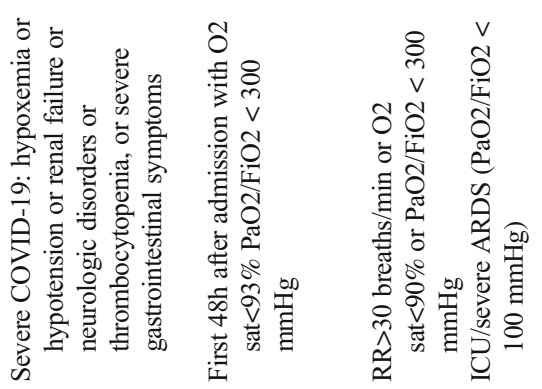

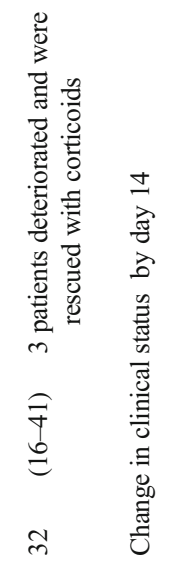

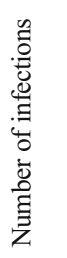

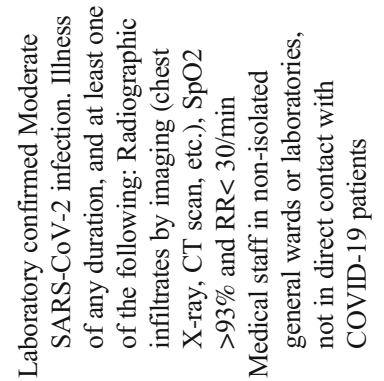

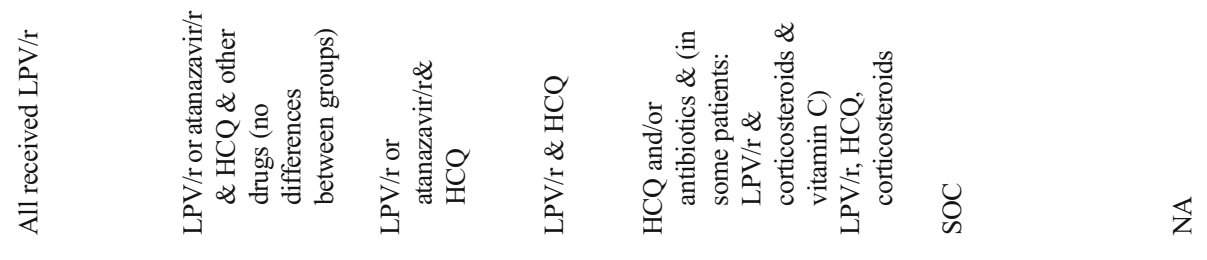

|

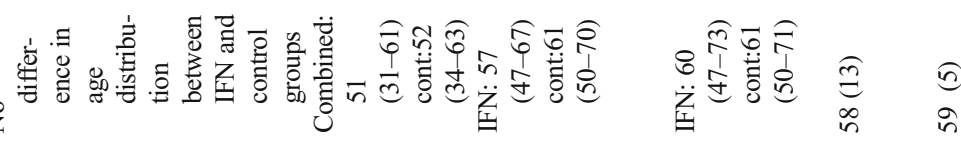

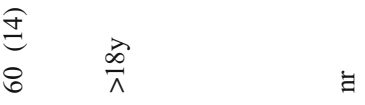

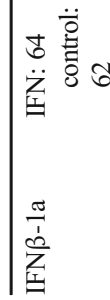

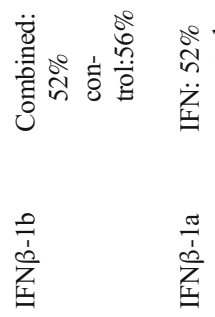

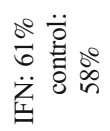

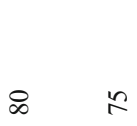

$\therefore$ 官

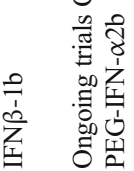




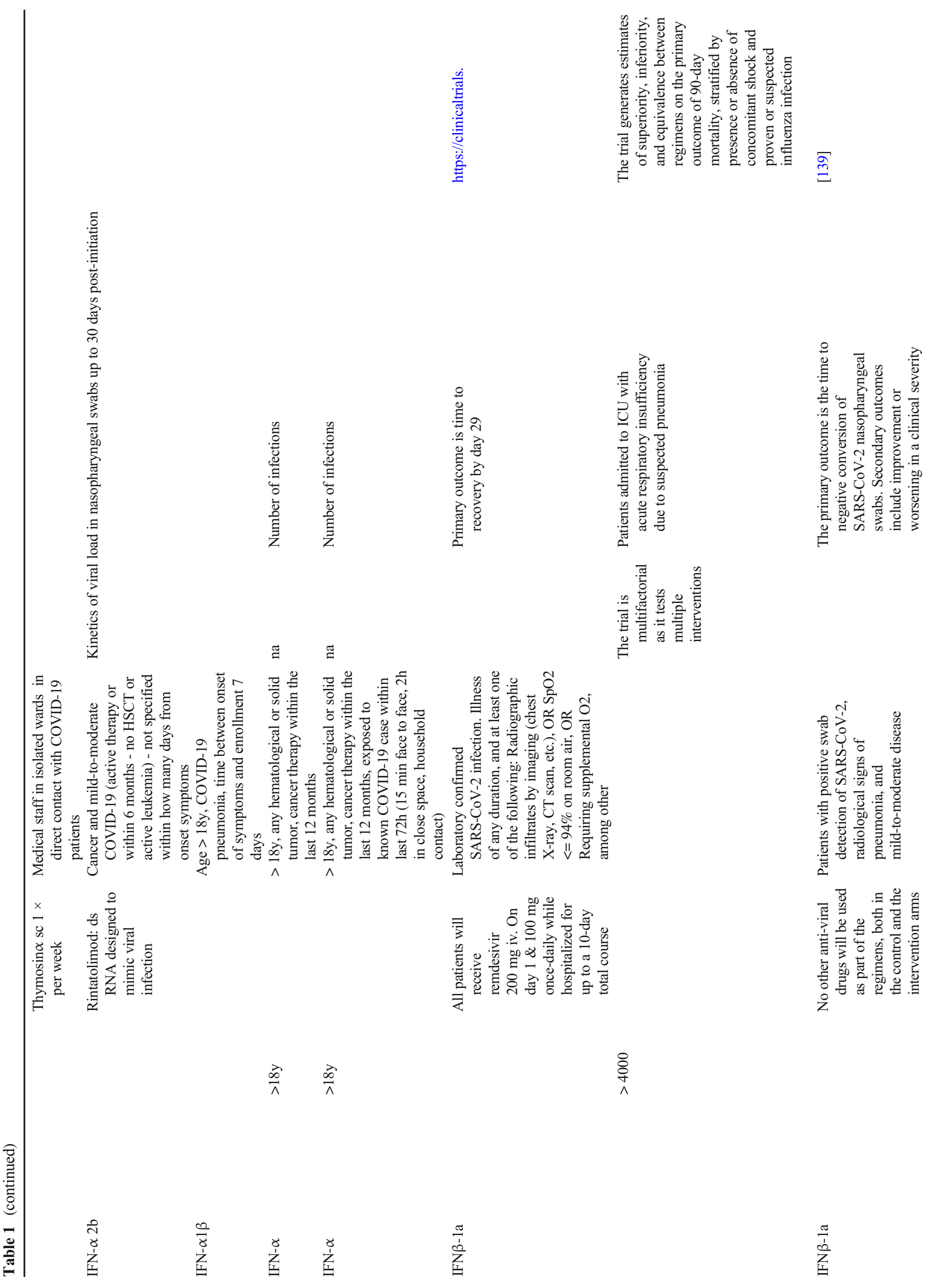




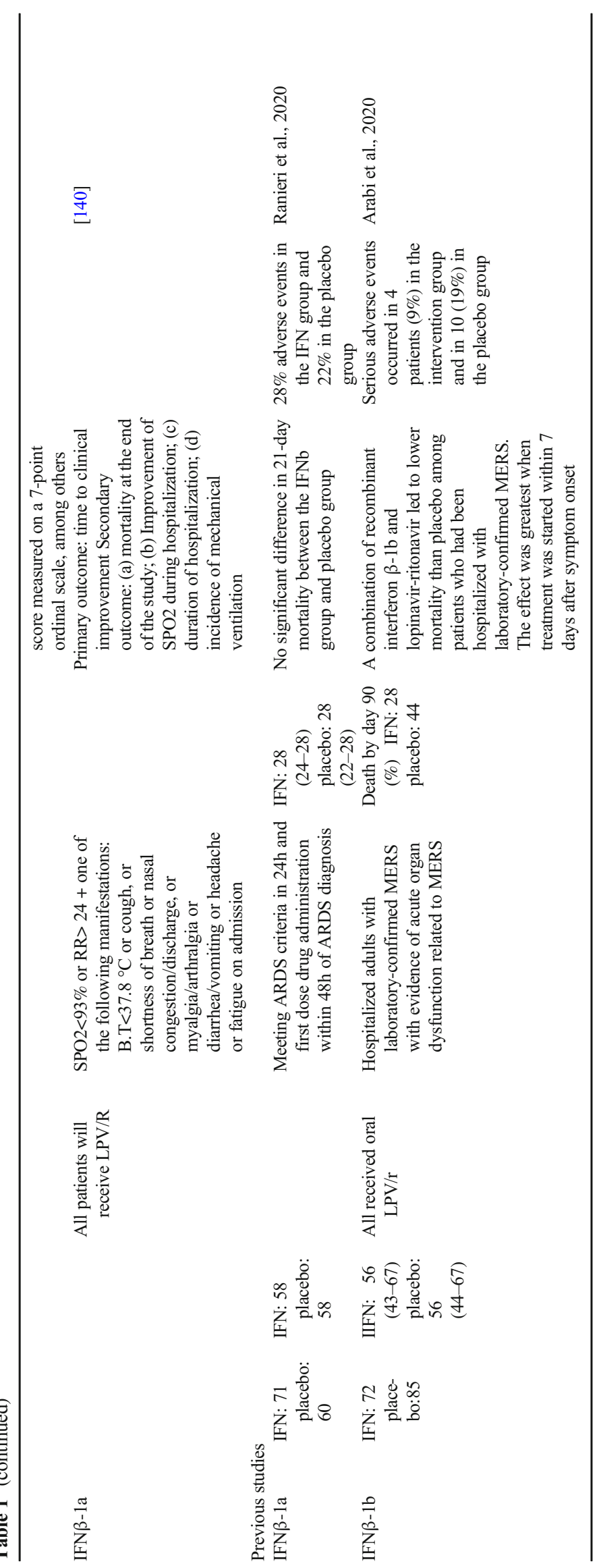


IFN- $\alpha 2$ b. In $89 \%$, nebulized IFN- $\alpha 2$ b was initiated within 5 days of admission, which was associated with reduced mortality. Late initiation of nebulized IFN- $\alpha 2 b$ therapy was associated with increased mortality [129]. A prospective exploratory trial in hospitalized patients compared inhaled IFN- $\alpha 2 b$ with or without umifenovir, a broadly acting anti-viral, to umifenovir alone [130]. IFN- $\alpha 2$ b was only included as a treatment arm when administered within 8 days of admission. The time to negative PCR was significantly shorter in patients receiving inhaled IFN- $\alpha 2 b$ [130]. Other trials included IFN- $\alpha 2$ in treatment arms with multiple drugs, including Chinese traditional medicine (Table 1). Overall, there has been a trend towards shorter duration of hospitalization and shorter time to negative SARS-CoV-2 PCR in patients admitted with COVID-19 pneumonia and treated with IFN- $\alpha 2$; however, interpretation of the data is hampered by the lack of a rigorously conducted DBRCT. Several protocols are currently recruiting hospitalized COVID-19 patients to study the efficacy and safety of administration within 7 days of symptom onset of s.c., i.v., or nebulized IFN- $\alpha 2$ (Table 1). Also, several trials will assess the efficacy of intranasal or nebulized IFN- $\alpha 2$ to prevent COVID-19 pneumonia. For instance, an Australian study will investigate the efficacy of IFN- $\alpha 2$ nose drops as a pre- or post-exposure prophylaxis in cancer patients. This trial in particular will be of interest as it can impact on the type I IFN deficiency in the first phase of COVID-19 infection, the time at which rapid induction of antiviral state is crucial.

\section{IFN- $\beta$ in COVID-19}

In the context of highly pathogenic coronaviruses, IFN- $\beta$ was reportedly more active than IFN- $\alpha$, at least in vitro, in its antiviral activity [141-143]. Moreover, most patients with auto-Abs to type I IFNs had auto-Abs to the 13 individual IFN- $\alpha$, including $\alpha 2$, and/or IFN- $\omega$, but only $2 \%$ of them also had auto-Abs to IFN- $\beta$, IFN-K, or IFN- $\varepsilon$ [4]. Thus, therapeutic use of IFN- $\beta$ should be a better choice than IFN- $\alpha$ from this viewpoint. Previous experience with another coronavirus, Middle East respiratory syndrome (MERS) virus, also supports this approach, with a clinical trial showing that IFN- $\beta 1$ b reduced mortality compared with placebo in hospitalized patients [144]. More trials with IFN- $\beta$ than with IFN- $\alpha 2$ have been reported in the context of COVID-19 (Table 1). Several trials failed to show a beneficial effect. Oral favipiravir plus inhaled IFN- $\beta$ failed to demonstrate any benefit when compared with hydroxychloroquine in terms of mortality, ICU admission, and inflammatory markers in hospitalized patients with moderate-to-severe COVID-19 pneumonia in an open-label randomized trial [145]. Similarly, the WHO Solidarity Trial failed to show a reduction in mortality in the s.c. and i.v. IFN- $\beta 1$ a treatment arms.
However, about $50 \%$ of these patients received corticosteroids, which may have blunted the IFN effect [134]. Importantly, the adaptive COVID-19 treatment trial 3 (ACTT3) compared remdesivir plus placebo to remdesivir plus s.c. IFN- $\beta 1 \mathrm{a}$ and was halted prematurely in hospitalized patients receiving high-flow oxygen when interim data showed potential harm from subcutaneous IFN- $\beta 1 \mathrm{a}$. In contrast, no harm was observed in patients receiving low-flow or no oxygen, in whom the efficacy of IFN- $\beta 1 \mathrm{a}$ is still being evaluated. On the other hand, some trials seem to show a benefit. A prospective, open-label, randomized single-center trial reported no significant difference in time to clinical response, but lower mortality at day 28 when s.c. IFN- $\beta 1$ a was added to treatment arms at median 10 days after onset of symptoms in hospitalized patients (Table 1) [133]. IFN- $\beta 1 \mathrm{~b}$ s.c. plus lopinavir/ritonavir and ribavirin started at median 5 days in patients hospitalized with COVID-19 pneumonia resulted in shorter time to negative PCR in the triple treatment arm versus the lopinavir/ritonavir alone [132]. In an openlabel RCT including severe COVID-19 patients, time to clinical improvement was shorter in the IFN- $\beta 1$ b s.c. group $(p=0.002)$ and ICU admission rate higher in the control group $(p=0.04)$ [134]. Finally, in a double-blind RCT, daily inhaled IFN $\beta$-1a for 14 days in admitted patients led to a faster and stronger clinical improvement on the WHO Ordinal Scale for Clinical Improvement compared with placebo [131]. The patients had a median duration of symptoms of 10 days at recruitment and IFN- $\beta$ was given for 14 days and was well tolerated. More trials are on the way, focusing on either ventilated COVID-19 patients or ambulatory patients to study the impact of late and early (at home) intervention with IFN- $\beta$ (Table 1). Overall, the trials are inconclusive, potentially due to the relatively late administration of IFNs.

\section{A Proposal: Early IFN- $\beta$ in the Outpatient Setting}

The two-step pathophysiology model of severe COVID-19 pneumonia suggests that early administration of IFN- $\beta$ at the onset of SARS-CoV-2 infection, or even prior to infection in exposed individuals, may halt disease progression [5]. Especially at risk are individuals above age 65 years and individuals of any age with genetic defects of the type I IFN response pathway or with neutralizing anti-type I IFN autoAbs. Several lines of evidence point to advantages in using IFN- $\beta$. First, in vitro data indicate higher efficacy of IFN- $\beta$ against highly pathogenic coronaviruses. Second, the trials with IFN- $\beta$ in MERS support its use, without neglecting the need for caution raised by the ACTT- 3 trial. Third and most importantly, the auto-Abs to type I IFN neutralized the 13 IFN- $\alpha$ and IFN- $\omega$ but very rarely IFN- $\beta$. Among individuals at risk, either (A) a close contact of an index case (i.e., exposed 
but negative for SARS-CoV-2), (B) an asymptomatic infected subject, or (C) an ambulatory (mildly symptomatic) patient may benefit from early IFN- $\beta$ administration, i.e., as soon as possible post-exposure or post-infection. Indeed, the peak viral load on nasopharyngeal swab occurs at or even prior to onset of symptoms [146]. These three groups need distinct clinical trials to assess the efficacy of early IFN- $\beta$ therapy in mitigating disease and viral shedding, as well as safety. Individuals vaccinated adequately against the viral variant diagnosed in the contact or themselves may or may not be considered. Of course, this presumes that viral strain testing can be performed with a short turnaround time. As outlined above, IFN- $\beta$ can be administered via several routes, including i.m., s.c. (Pegylated form), nebulized, or a combination thereof. Nebulized IFN- $\beta$ is likely to be of benefit early pre- or postinfection, owing to its local effect, whereas s.c./i.m. acts systemically and is likely to be effective beyond the first days post-infection. Thus, one could envisage having trials of postexposure prophylaxis by nebulized IFN- $\beta$ acting locally for the duration of the incubation time (14 days) in group (A), combined with s.c./i.m. IFN- $\beta$ for systemic action in groups (B) and (C). Alternatively, all three groups could receive a single s.c. injection of peg-IFN- $\beta$. The advantage of pegylated IFN- $\beta$ is that a single subcutaneous injection is sufficient and can easily be given in the outpatient setting. This early intervention with IFN- $\beta$ in individuals at risk may theoretically alleviate the lack of type I IFN signaling early post-exposure or post-infection, the first phase of COVID-19 disease, by rapid induction of an anti-viral state, and may mitigate the natural evolution of SARS-CoV-2 infection to potentially fatal disease.

\section{Type III IFN: IFN- $\lambda$}

The IFN- $\lambda$ family of cytokines can be produced by a number of cell types, including macrophages and plasmacytoid dendritic cells, in response to viral stimulation [147]. Like the type I IFN, they can establish an antiviral state; however, they do so through a distinct receptor complex primarily expressed on epithelial cells, including those in the respiratory tract. Signalling by type I or type III IFN shares overlapping antiviral IFN-stimulated gene (ISG) expression [148], suggesting that IFN- $\lambda$ may potentially substitute or complement type I IFN therapy. In support of the latter, in vitro (using primary human airway epithelial cells) and mouse model data demonstrate that IFN- $\lambda$ (specifically, IFN- $\lambda 1$ a) reduces SARS-CoV2 replication when used either prophylactically or therapeutically $[149,150]$. Similar to what we propose with IFN- $\beta$, early outpatient treatment of persons infected with SARS$\mathrm{CoV}-2$ using peg-IFN- $\lambda$ has been studied. Patients who were either within 7 days of symptom onset or at first positive test if asymptomatic were treated with a single s.c. dose of peg-
IFN- $\lambda$ or placebo ( $N=30$ per group) [151]. Those receiving peg-IFN- $\lambda$ demonstrated faster viral clearance by day 7 . Treatment tolerance was similar to placebo. Although the study was not powered to look at clinical evolution, 5 $(16.7 \%)$ in the placebo group and $1(3.3 \%)$ in the peg-IFN- $\lambda$ group required visit to the emergency room by day 14 . On the other hand, another study with a similar design showed that peg-IFN- $\lambda$ did not shorten the duration of viral shedding [152]. Differences in results between these two studies may be due to differences in baseline viral loads (58\% of subjects with $>6.0 \mathrm{log}$ copies $/ \mathrm{ml}$ in the former vs. $75 \%$ with $<5.5 \mathrm{log}$ copies $/ \mathrm{ml}$ in the latter) as well as differences in SARS-CoV-2 antibody positivity at baseline $(0 \%$ in the treatment group and $10 \%$ in the placebo group in the former vs. $25 \%$ in the treatment group and $46.7 \%$ in the placebo group in the latter).

Although additional studies are needed, these studies provide proof of principle that a single dose of adjunctive pegIFN- $\lambda$ can be administered early following infection, is well tolerated, and may provide enhanced virological clearance especially in those with high viral load or delayed seroconversion. Whether this treatment impacts hospitalization or transmission requires further investigation. However, several caveats are in place. First, there is currently no genetic or immunological evidence that insufficient IFN- $\lambda$ immunity can underlie severe COVID-19 pneumonia. Second, prolonged IFN- $\lambda$ signaling has been described to disrupt lung epithelial repair following viral infection more potently than IFN- $\alpha$ and $-\beta$ [153]. Third, sustained type III IFN signaling in inflamed lungs led to increased susceptibility to bacterial infection, at least in a mouse model [154]. Thus, the epithelial distribution of IFN- $\lambda$ receptors may be disadvantageous rather than helpful in limiting the effects of this IFN to the epithelia. Fourth, we are still in the learning curve on IFN- $\lambda$ as a treatment, both in terms of safety and side effect profile, but also in terms of pharmacokinetics and pharmacodynamics, favoring the preferential use of IFN- $\beta$ in future trials aimed at preventing evolution to severe COVID-19 in individuals at risk.

\section{Conclusion}

Insight that type I IFN defects underlie severe COVID-19 in at least $10 \%$ of patients challenges past, ongoing, and future trials and clinical treatment strategies. Here, we discussed how findings from the COVIDhge provide a rationale for targeted interventions during specific phases of COVID-19 pathogenesis. Early testing can identify individuals with defects in the type I IFN circuit, whether genetically or serologically mediated, who stand to most benefit from IFN- $\beta$ therapy prior to or during the early viral replication phase. In addition, the efficacy of IFN- $\beta$ therapy would not be anticipated to be affected by the infecting SARS-CoV-2 variant. Those hospitalized and found to harbor neutralizing auto-Abs to type I 
IFN might benefit from TPE. Ideally, trials should be designed to specifically address these different treatment groups. Our findings also raise important questions about some of the current approaches being evaluated, e.g., the use of convalescent plasma and the use of Jakinibs. Finally, despite the advent of efficacious vaccines in the general population, patients with defects of type I IFN immunity may continue to remain at risk, for example, due to impaired innate responses in the face of emerging variants or to sub-optimal adaptive immunity. The ongoing work of our consortium, in conjunction with the recent promising results of IFN- $\beta$ in treatment of SARS-CoV-2 infection, opens bold new avenues in the global fight against this pandemic.

Availability of Data and Materials Not applicable for this commentary.

Author Contribution DV, LA, PB, MC, AC, PG, FH, MC, DH, PS, AP, $\mathrm{APu}, \mathrm{LN}, \mathrm{QZ}, \mathrm{HS}, \mathrm{JLC}$, and IM wrote the manuscript. DV, JLC, and IM edited the manuscript. All authors commented and approved the final version.

Funding D.C.V. is supported by the Fonds de la recherche en santé du Québec clinician-scientist scholar Junior 2 program.

L.D.N. and H.C.S. are supported by the Intramural Research Program of the National Institute of Allergy and Infectious Diseases, National Institutes of Health.

The Laboratory of Human Genetics of Infectious Diseases is supported by the Howard Hughes Medical Institute, the Rockefeller University, the St. Giles Foundation, the National Institutes of Health (NIH) (R01AI088364), the National Center for Advancing Translational Sciences (NCATS), NIH Clinical and Translational Science Award (CTSA) program (UL1 TR001866), a Fast Grant from Emergent Ventures, Mercatus Center at George Mason University, the Yale Center for Mendelian Genomics and the GSP Coordinating Center funded by the National Human Genome Research Institute (NHGRI) (UM1HG006504 and U24HG008956), the Fisher Center for Alzheimer's Research Foundation, the Meyer Foundation, the French National Research Agency (ANR) under the "Investments for the Future" program (ANR-10-IAHU-01), the Integrative Biology of Emerging Infectious Diseases Laboratory of Excellence (ANR-10LABX-62-IBEID), the French Foundation for Medical Research (FRM) (EQU201903007798), the FRM and ANR GENCOVID project, ANRSCOV05, the Square Foundation, Grandir - Fonds de solidarité pour l'enfance, the SCOR Corporate Foundation for Science, Institut National de la Santé et de la Recherche Médicale (INSERM), and the University of Paris.

$\mathrm{PB}$ is supported by the MD-PhD program of the Imagine Institute (with the support of the Fondation Bettencourt-Schueller). I.M. is a Senior Clinical Investigator at the Research Foundation - Flanders, and is chair of the CSL Behring Chair of Primary Immunodeficiencies at KU Leuven, by the KU Leuven C1 Grant C16/18/007, by a VIB GC PID Grant, by the FWO Grants G0C8517N, G0B5120N, and G0E8420N, and by the Jeffrey Modell Foundation. This work is supported by ERN-RITA.

\section{Declarations}

Ethical Statement; Consent to Participate; Consent to Publish No ethical approval required. Consent to publish not applicable. Consent to publish not applicable.
Competing Interests The authors declare no competing interests.

\section{References}

1. NIH. Clinical spectrum of SARS-CoV-2 infection December 17, 2020 [Available from: https://www.covid19treatmentguidelines. nih.gov/overview/clinical-spectrum/.

2. Johns Hopkins University \& Medicine CRC. https://coronavirus. jhu.edu/map.html 2021 [

3. Zhang Q, Bastard P, Liu Z, Le Pen J, Moncada-Velez M, Chen J, et al. Inborn errors of type I IFN immunity in patients with lifethreatening COVID-19. Science. 2020;370(6515).

4. Bastard P, Rosen LB, Zhang Q, Michailidis E, Hoffmann HH, Zhang Y, et al. Autoantibodies against type I IFNs in patients with life-threatening COVID-19. Science. 2020;370(6515).

5. Zhang Q, Bastard P, Bolze A, Jouanguy E, Zhang SY, Effort CHG, et al. Life-threatening COVID-19: defective interferons unleash excessive inflammation. Med (N Y). 2020;1(1):14-20.

6. Hadjadj J, Yatim N, Barnabei L, Corneau A, Boussier J, Smith N, et al. Impaired type I interferon activity and inflammatory responses in severe COVID-19 patients. Science. 2020;369(6504): 718-24.

7. Trouillet-Assant S, Viel S, Gaymard A, Pons S, Richard JC, Perret $\mathrm{M}$, et al. Type I IFN immunoprofiling in COVID-19 patients. The Journal of Allergy and Clinical Immunology. 2020;146(1):206-8 e2.

8. Blanco-Melo D, Nilsson-Payant BE, Liu WC, Uhl S, Hoagland D, Moller R, et al. Imbalanced host response to SARS-CoV-2 drives development of COVID-19. Cell. 2020;181(5):1036-45 e9.

9. Meffre E, Iwasaki A. Interferon deficiency can lead to severe COVID. Nature. 2020;587(7834):374-6.

10. Beck DB, Aksentijevich I. Susceptibility to severe COVID-19. Science. 2020;370(6515):404-5.

11. Troya J, Bastard P, Planas-Serra L, Ryan P, Ruiz M, de Carranza $M$, et al. Neutralizing autoantibodies to type I IFNs in $>10 \%$ of patients with severe COVID-19 pneumonia hospitalized in Madrid, Spain. J Clin Immunol. 2021.

12. Koning R, Bastard P, Casanova JL, Brouwer MC, van de Beek D, with the Amsterdam UMCC-BI. Autoantibodies against type I interferons are associated with multi-organ failure in COVID-19 patients. Intensive Care Med. 2021.

13. van der Wijst MGP, Vazquez SE, Hartoularos GC, Bastard P, Grant T, Bueno R, et al. Longitudinal single-cell epitope and RNA-sequencing reveals the immunological impact of type 1 interferon autoantibodies in critical COVID-19. bioRxiv. 2021.

14. Goncalves D. Antibodies against type-I Interferon: detection and association with severe clinical outcome in COVID-19 patients. medRxiv. 2021.

15. Vazquez SE, Bastard P, Kelly K et al. Neutralizing Autoantibodies to Type I Interferons in COVID-19 Convalescent Donor Plasma. J Clin Immunol 2021;1-3. https://doi.org/10.1007/s10875-02101060-0.

16. Consortium WHOST, Pan H, Peto R, Henao-Restrepo AM, Preziosi MP, Sathiyamoorthy V, et al. Repurposed antiviral drugs for Covid-19 - interim WHO Solidarity Trial results. N Engl J Med. 2021;384(6):497-511.

17. Challen R, Brooks-Pollock E, Read JM, Dyson L, TsanevaAtanasova K, Danon L. Risk of mortality in patients infected with SARS-CoV-2 variant of concern 202012/1: matched cohort study. BMJ. 2021;372:n579.

18. Garcia-Beltran WF, Lam EC, St Denis K, Nitido AD, Garcia ZH, Hauser BM, et al. Multiple SARS-CoV-2 variants escape neutralization by vaccine-induced humoral immunity. Cell. 2021;184(9): 2523. 
19. Le Bon A, Schiavoni G, D’Agostino G, Gresser I, Belardelli F, Tough DF. Type I interferons potently enhance humoral immunity and can promote isotype switching by stimulating dendritic cells in vivo. Immunity. 2001;14(4):461-70.

20. Moens L, Van Eyck L, Jochmans D, Mitera T, Frans G, Bossuyt $\mathrm{X}$, et al. A novel kindred with inherited STAT2 deficiency and severe viral illness. The Journal of allergy and clinical immunology. 2017;S0091-6749(16):31440-3.

21. Meyts I, Casanova JL. Viral infections in humans and mice with genetic deficiencies of the type I IFN response pathway. European Journal of Immunology. 2021.

22. Bastard P. Anti-IFN autoantibodies and YFV disease. The Journal of Experimental Medicine. 2021.

23. Bloch EM, Shoham S, Casadevall A, Sachais BS, Shaz B, Winters JL, et al. Deployment of convalescent plasma for the prevention and treatment of COVID-19. J Clin Invest. 2020;130(6):2757-65.

24. Casadevall A, Dadachova E, Pirofski LA. Passive antibody therapy for infectious diseases. Nat Rev Microbiol. 2004;2(9):695703.

25. Pandey S, Vyas GN. Adverse effects of plasma transfusion. Transfusion. 2012;52(Suppl 1):65S-79S.

26. Arvin AM, Fink K, Schmid MA, Cathcart A, Spreafico R, Havenar-Daughton C, et al. A perspective on potential antibodydependent enhancement of SARS-CoV-2. Nature. 2020;584(7821):353-63.

27. Chai KL, Valk SJ, Piechotta V, Kimber C, Monsef I, Doree C, et al. Convalescent plasma or hyperimmune immunoglobulin for people with COVID-19: a living systematic review. Cochrane Database Syst Rev. 2020;10:CD013600.

28. Wooding DJ, Bach H. Treatment of COVID-19 with convalescent plasma: lessons from past coronavirus outbreaks. Clin Microbiol Infect. 2020;26(10):1436-46.

29. Vegivinti CTR, Pederson JM, Saravu K, Gupta N, Evanson KW, Kamrowski S, et al. Efficacy of convalescent plasma therapy for COVID-19: a systematic review and meta-analysis. J Clin Apheresis. 2021.

30. Simonovich VA, Burgos Pratx LD, Scibona P, Beruto MV, Vallone MG, Vazquez C, et al. A randomized trial of convalescent plasma in Covid-19 severe pneumonia. N Engl J Med. 2021;384(7):619-29.

31. Libster R, Perez Marc G, Wappner D, Coviello S, Bianchi A, Braem V, et al. Early high-titer plasma therapy to prevent severe Covid-19 in older adults. N Engl J Med. 2021;384(7):610-8.

32. Barone P, DeSimone RA. Convalescent plasma to treat coronavirus disease 2019 (COVID-19): considerations for clinical trial design. Transfusion. 2020;60(6):1123-7.

33. Subbarao K, Mordant F, Rudraraju R. Convalescent plasma treatment for COVID-19: tempering expectations with the influenza experience. Eur J Immunol. 2020;50(10):1447-53.

34. Chen P, Nirula A, Heller B, Gottlieb RL, Boscia J, Morris J, et al. SARS-CoV-2 neutralizing antibody LY-CoV555 in outpatients with Covid-19. The New England journal of medicine. 2021;384(3):229-37.

35. Weinreich DM, Sivapalasingam S, Norton T, Ali S, Gao H, Bhore $\mathrm{R}$, et al. REGN-COV2, a neutralizing antibody cocktail, in outpatients with Covid-19. The New England Journal of Medicine. 2021;384(3):238-51.

36. Gottlieb RL, Nirula A, Chen P, Boscia J, Heller B, Morris J, et al. Effect of bamlanivimab as monotherapy or in combination with etesevimab on viral load in patients with mild to moderate COVID-19: a randomized clinical trial. Jama. 2021;325(7):63244.

37. Starr TN, Greaney AJ, Addetia A, Hannon WW, Choudhary MC, Dingens AS, et al. Prospective mapping of viral mutations that escape antibodies used to treat COVID-19. Science. 2021;371(6531):850-4.
38. Gelfand EW. Intravenous immune globulin in autoimmune and inflammatory diseases. N Engl J Med. 2012;367(21):2015-25.

39. Cao W, Liu X, Bai T, Fan H, Hong K, Song H, et al. High-dose intravenous immunoglobulin as a therapeutic option for deteriorating patients with coronavirus disease 2019. Open Forum Infectious Diseases. 2020;7(3):ofaa102.

40. $\mathrm{Lin} \mathrm{L}, \mathrm{Lu} \mathrm{L}, \mathrm{Cao} \mathrm{W}, \mathrm{Li}$ T. Hypothesis for potential pathogenesis of SARS-CoV-2 infection-a review of immune changes in patients with viral pneumonia. Emerging Microbes \& Infections. 2020;9(1):727-32.

41. Mohtadi N, Ghaysouri A, Shirazi S, Sara A, Shafiee E, Bastani E, et al. Recovery of severely ill COVID-19 patients by intravenous immunoglobulin (IVIG) treatment: A case series. Virology. 2020;548:1-5.

42. Zhang J, Yang Y, Yang N, Ma Y, Zhou Q, Li W, et al. Effectiveness of intravenous immunoglobulin for children with severe COVID-19: a rapid review. Annals of Translational Medicine. 2020;8(10):625.

43. Liu X, Cao W, Li T. High-dose intravenous immunoglobulins in the treatment of severe acute viral pneumonia: the known mechanisms and clinical effects. Frontiers in Immunology. 2020;11: 1660.

44. Morris SB, Schwartz NG, Patel P, Abbo L, Beauchamps L, Balan $\mathrm{S}$, et al. Case series of multisystem inflammatory syndrome in adults associated with SARS-CoV-2 infection - United Kingdom and United States, March-August 2020. MMWR Morbidity and Mortality Weekly Report. 2020;69(40):1450-6.

45. Ouldali N, Toubiana J, Antona D, Javouhey E, Madhi F, Lorrot $\mathrm{M}$, et al. Association of intravenous immunoglobulins plus methylprednisolone vs immunoglobulins alone with course of fever in multisystem inflammatory syndrome in children. Jama. 2021.

46. Shao Z, Feng Y, Zhong L, Xie Q, Lei M, Liu Z, et al. Clinical efficacy of intravenous immunoglobulin therapy in critical ill patients with COVID-19: a multicenter retrospective cohort study. Clinical \& Translational Immunology. 2020;9(10):e1192.

47. Tabarsi P, Barati S, Jamaati H, Haseli S, Marjani M, Moniri A, et al. Evaluating the effects of intravenous immunoglobulin (IVIg) on the management of severe COVID-19 cases: a randomized controlled trial. Int Immunopharmacol. 2021;90:107205.

48. Gharebaghi N, Nejadrahim R, Mousavi SJ, Sadat-Ebrahimi SR, Hajizadeh R. The use of intravenous immunoglobulin gamma for the treatment of severe coronavirus disease 2019: a randomized placebo-controlled double-blind clinical trial. BMC Infect Dis. 2020;20(1):786.

49. Peter HH, Ochs HD, Cunningham-Rundles C, Vinh DC, Kiessling P, Greve B, et al. Targeting FcRn for immunomodulation: benefits, risks, and practical considerations. The Journal of Allergy and Clinical Immunology. 2020;146(3): 479-91.e5.

50. Benesch M, Kerbl R, Lackner H, Berghold A, Schwinger W, Triebl-Roth K, et al. Low-dose versus high-dose immunoglobulin for primary treatment of acute immune thrombocytopenic purpura in children: results of a prospective, randomized single-center trial. Journal of Pediatric Hematology/Oncology. 2003;25(10):797800 .

51. van Doorn PA, Ruts L, Jacobs BC. Clinical features, pathogenesis, and treatment of Guillain-Barré syndrome. The Lancet Neurology. 2008;7(10):939-50.

52. Group RC, Horby P, Lim WS, Emberson JR, Mafham M, Bell JL, et al. Dexamethasone in hospitalized patients with Covid-19. N Engl J Med. 2021;384(8):693-704.

53. Group WHOREAfC-TW, Sterne JAC, Murthy S, Diaz JV, Slutsky AS, Villar J, et al. Association between administration of systemic corticosteroids and mortality among critically ill patients with COVID-19: a meta-analysis. Jama. 2020;324(13): $1330-41$. 
54. Stone JH, Frigault MJ, Serling-Boyd NJ, Fernandes AD, Harvey L, Foulkes AS, et al. Efficacy of tocilizumab in patients hospitalized with Covid-19. N Engl J Med. 2020;383(24):2333-44.

55. Hermine O, Mariette X, Tharaux PL, Resche-Rigon M, Porcher R, Ravaud P, et al. Effect of tocilizumab vs usual care in adults hospitalized with COVID-19 and moderate or severe pneumonia: a randomized clinical trial. JAMA Intern Med. 2021;181(1):3240.

56. Salvarani C, Dolci G, Massari M, Merlo DF, Cavuto S, Savoldi L, et al. Effect of tocilizumab vs standard care on clinical worsening in patients hospitalized with COVID-19 pneumonia: a randomized clinical trial. JAMA Intern Med. 2021;181(1):24-31.

57. Rosas IO, Brau N, Waters M, Go RC, Hunter BD, Bhagani S, et al. Tocilizumab in hospitalized patients with severe Covid-19 pneumonia. N Engl J Med. 2021

58. Klopfenstein T, Zayet S, Lohse A, Balblanc JC, Badie J, Royer PY, et al. Tocilizumab therapy reduced intensive care unit admissions and/or mortality in COVID-19 patients. Med Mal Infect. 2020;50(5):397-400.

59. Salama C, Han J, Yau L, Reiss WG, Kramer B, Neidhart JD, et al. Tocilizumab in patients hospitalized with Covid-19 pneumonia. N Engl J Med. 2021;384(1):20-30.

60. Veiga VC, Prats J, Farias DLC, Rosa RG, Dourado LK, Zampieri FG, et al. Effect of tocilizumab on clinical outcomes at 15 days in patients with severe or critical coronavirus disease 2019: randomised controlled trial. BMJ. 2021;372:n84.

61. Investigators R-C, Gordon AC, Mouncey PR, Al-Beidh F, Rowan $\mathrm{KM}$, Nichol AD, et al. Interleukin-6 receptor antagonists in critically ill patients with Covid-19. N Engl J Med. 2021.

62. Rubin EJ, Longo DL, Baden LR. Interleukin-6 receptor inhibition in Covid-19 - cooling the inflammatory soup. N Engl J Med. 2021.

63. Gadina M, Chisolm DA, Philips RL, McInness IB, Changelian PS, O'Shea JJ. Translating JAKs to Jakinibs. J Immunol. 2020;204(8):2011-20.

64. Lauwerys BR, Hachulla E, Spertini F, Lazaro E, Jorgensen C, Mariette X, et al. Down-regulation of interferon signature in systemic lupus erythematosus patients by active immunization with interferon alpha-kinoid. Arthritis Rheum. 2013;65(2):447-56.

65. Meyts I, Bucciol G, Quinti I, Neven B, Fischer A, Seoane E, et al. Coronavirus disease 2019 in patients with inborn errors of immunity: an international study. The Journal of Allergy and Clinical Immunology. 2020;147(2):520-31.

66. Kalil AC, Patterson TF, Mehta AK, Tomashek KM, Wolfe CR, Ghazaryan V, et al. Baricitinib plus remdesivir for hospitalized adults with Covid-19. The New England Journal of Medicine. 2020.

67. Beigel JH, Tomashek KM, Dodd LE, Mehta AK, Zingman BS, Kalil AC, et al. Remdesivir for the treatment of Covid-19 - Final Report. N Engl J Med. 2020;383(19):1813-26.

68. Cao Y, Wei J, Zou L, Jiang T, Wang G, Chen L, et al. Ruxolitinib in treatment of severe coronavirus disease 2019 (COVID-19): a multicenter, single-blind, randomized controlled trial. The Journal of Allergy and Clinical Immunology. 2020;146(1):137-46 e3.

69. Browne SK, Zaman R, Sampaio EP, Jutivorakool K, Rosen LB, Ding L, et al. Anti-CD20 (rituximab) therapy for anti-IFN- $\gamma$ autoantibody-associated nontuberculous mycobacterial infection. Blood. 2012;119(17):3933-9.

70. Czaja CA, Merkel PA, Chan ED, Lenz LL, Wolf ML, Alam R, et al. Rituximab as successful adjunct treatment in a patient with disseminated nontuberculous mycobacterial infection due to acquired anti-interferon- $\gamma$ autoantibody. Clinical Infectious Diseases. 2014;58(6):e115-8.

71. Yerramilli A, Huang GKL, Griffin DWJ, Kong KL, Muhi S, Muttucumaru RS, et al. Disseminated nontuberculous mycobacterial infection associated with acquired immunodeficiency due to anti-interferon $\gamma$ autoantibodies. Open Forum Infectious Diseases. 2019;6(4):ofz131.

72. Naik R, Cortes JA. Persistent Mycobacterium abscessus infection secondary to interferon- $\gamma$ autoantibodies. Annals of Allergy, Asthma \& Immunology. 2016;116(5):461-2.

73. Pruetpongpun N, Khawcharoenporn T, Damronglerd P, Suthiwartnarueput W, Apisarnthanarak A, Rujanavej S, et al. Disseminated Talaromyces marneffei and Mycobacterium abscessus in a patient with anti-interferon- $\gamma$ autoantibodies. Open Forum Infectious Diseases. 2016;3(2):ofw093.

74. Shah UA, Mailankody S. Emerging immunotherapies in multiple myeloma. BMJ (Clinical research ed). 2020;370:m3176.

75. Even-Or E, Naser Eddin A, Shadur B, Dinur Schejter Y, Najajreh $\mathrm{M}$, Zelig $\mathrm{O}$, et al. Successful treatment with daratumumab for post-HSCT refractory hemolytic anemia. Pediatric Blood \& Cancer. 2020;67(1):e28010.

76. Ratuszny D, Skripuletz T, Wegner F, Groß M, Falk C, Jacobs R, et al. Case report: daratumumab in a patient with severe refractory anti-NMDA receptor encephalitis. Frontiers in Neurology. 2020;11:602102.

77. Bag-Ozbek A, Hui-Yuen JS. Emerging B-cell therapies in systemic lupus erythematosus. Therapeutics and Clinical Risk Management. 2021;17:39-54.

78. Ochoa S, Ding L, Kreuzburg S, Treat J, Holland SM, Zerbe CS. Daratumumab (anti-CD38) for treatment of disseminated nontuberculous mycobacteria in a patient with anti-IFN- $\gamma$ autoantibodies. Clin Infect Dis 2020.

79. Fallet B, Kyburz D, Walker UA. Mild course of COVID-19 and spontaneous virus clearance in a patient with depleted peripheral blood B cells due to rituximab treatment. Arthritis \& Rheumatology (Hoboken, NJ). 2020;72(9):1581-2.

80. Monti S, Montecucco C. Diagnostic and therapeutic challenges for patients with ANCA-associated vasculitides at the time of COVID-19. Response to: 'Rituximab for granulomatosis with polyangiitis in the pandemic of COVID-19: lessons from a case with severe pneumonia' by Guilpain et al. Annals of the Rheumatic Diseases. 2021;80(1):e11.

81. Sanchez-Piedra C, Diaz-Torne C, Manero J, Pego-Reigosa JM, Rúa-Figueroa Í, Gonzalez-Gay MA, et al. Clinical features and outcomes of COVID-19 in patients with rheumatic diseases treated with biological and synthetic targeted therapies. Annals of the Rheumatic Diseases. 2020;79(7):988-90.

82. Loarce-Martos J, Garcia-Fernandez A, Lopez-Gutierrez F, GarciaGarcia V, Calvo-Sanz L, Del Bosque-Granero I, et al. High rates of severe disease and death due to SARS-CoV-2 infection in rheumatic disease patients treated with rituximab: a descriptive study. Rheumatol Int. 2020;40(12):2015-21.

83. Kow CS, Hasan SS. Use of rituximab and the risk of adverse clinical outcomes in COVID-19 patients with systemic rheumatic disease. Rheumatol Int. 2020;40(12):2117-8.

84. Soresina A, Moratto D, Chiarini M, Paolillo C, Baresi G, Focà E, et al. Two X-linked agammaglobulinemia patients develop pneumonia as COVID-19 manifestation but recover. Pediatric Allergy and Immunology. 2020;31(5):565-9.

85. Quinti I, Lougaris V, Milito C, Cinetto F, Pecoraro A, Mezzaroma I, et al. A possible role for B cells in COVID-19? Lesson from patients with agammaglobulinemia. The Journal of allergy and clinical immunology. 2020;146(1):211-3.e4.

86. Papp KA, Haraoui B, Kumar D, Marshall JK, Bissonnette R, Bitton A, et al. Vaccination guidelines for patients with immunemediated disorders on immunosuppressive therapies. Journal of Cutaneous Medicine and Surgery. 2019;23(1):50-74.

87. Thibaud S, Tremblay D, Bhalla S, Zimmerman B, Sigel K, Gabrilove J. Protective role of Bruton tyrosine kinase inhibitors in patients with chronic lymphocytic leukaemia and COVID-19. British Journal of Haematology. 2020;190(2):e73-e6. 
88. Roschewski M, Lionakis MS, Sharman JP, Roswarski J, Goy A, Monticelli MA, et al. Inhibition of Bruton tyrosine kinase in patients with severe COVID-19. Sci Immunol. 2020;5(48).

89. Kos I, Balensiefer B, Roth S, Ahlgrimm M, Sester M, Schmidt T, et al. Prolonged course of COVID-19-associated pneumonia in a B-cell depleted patient after rituximab. Frontiers in Oncology. 2020;10:1578.

90. Yasuda H, Tsukune Y, Watanabe N, Sugimoto K, Uchimura A, Tateyama M, et al. Persistent COVID-19 pneumonia and failure to develop anti-SARS-CoV-2 antibodies during rituximab maintenance therapy for follicular lymphoma. Clinical Lymphoma, Myeloma \& Leukemia. 2020;20(11):774-6.

91. Leipe J, Wilke EL, Ebert MP, Teufel A, Reindl W. Long, relapsing, and atypical symptomatic course of COVID-19 in a B-celldepleted patient after rituximab. Seminars in Arthritis and Rheumatism. 2020;50(5):1087-8.

92. Schulze-Koops H, Krueger K, Vallbracht IV, Hasseli R, Skapenko A. Treatment of patients with inflammatory rheumatic diseases with rituximab should be carefully considered during the SARSCoV-2/COVID-19 pandemic. Response to: 'Persistence of rTPCR-SARS-CoV-2 infection and delayed serological response, as a possible effect of rituximab according to the hypothesis of Schulze-Koops et al' by Benucci et al. Annals of the rheumatic diseases. 2020.

93. Padmanabhan A, Connelly-Smith L, Aqui N, Balogun RA, Klingel R, Meyer E, et al. Guidelines on the use of therapeutic apheresis in clinical practice - evidence-based approach from the Writing Committee of the American Society for Apheresis: The Eighth Special Issue. Journal of Clinical Apheresis. 2019;34(3): 171-354.

94. Ishikawa T, Abe S, Kojima Y, Sano T, Iwanaga A, Seki KI, et al. Prediction of a sustained viral response in chronic hepatitis $\mathrm{C}$ patients who undergo induction therapy with double filtration plasmapheresis plus interferon-beta/ribavirin. Exp Ther Med. 2015;9(5):1646-50.

95. Jagdish K, Jacob S, Varughese S, David VG, Mohapatra A, Valson A, et al. Effect of double filtration plasmapheresis on various plasma components and patient safety: a prospective observational cohort study. Indian J Nephrol. 2017;27(5):377-83.

96. Liu X, Zhang Y, Xu X, Du W, Su K, Zhu C, et al. Evaluation of plasma exchange and continuous veno-venous hemofiltration for the treatment of severe avian influenza A (H7N9): a cohort study. Ther Apher Dial. 2015;19(2):178-84.

97. Patel P, Nandwani V, Vanchiere J, Conrad SA, Scott LK. Use of therapeutic plasma exchange as a rescue therapy in 2009 pH1N1 influenza $\mathrm{A}$-an associated respiratory failure and hemodynamic shock. Pediatr Crit Care Med. 2011;12(2):e87-9.

98. Adeli SH, Asghari A, Tabarraii R, Shajari R, Afshari S, Kalhor N, et al. Therapeutic plasma exchange as a rescue therapy in patients with coronavirus disease 2019: a case series. Pol Arch Intern Med. 2020;130(5):455-8.

99. Morath C, Weigand MA, Zeier M, Speer C, Tiwari-Heckler S, Merle U. Plasma exchange in critically ill COVID-19 patients. Crit Care. 2020;24(1):481.

100. Tabibi S, Tabibi T, Conic RRZ, Banisaeed N, Streiff MB. Therapeutic plasma exchange: a potential management strategy for critically ill COVID-19 patients. J Intensive Care Med. 2020;35(9):827-35.

101. Kesici S, Yavuz S, Bayrakci B. Get rid of the bad first: therapeutic plasma exchange with convalescent plasma for severe COVID-19. Proceedings of the National Academy of Sciences of the United States of America. 2020;117(23):12526-7.

102. Lin JH, Chen YC, Lu CL, Hsu YN, Wang WJ. Application of plasma exchange in association with higher dose CVVH in cytokine storm complicating COVID-19. J Formos Med Assoc. 2020;119(6):1116-8.
103. Ma J, Xia P, Zhou Y, Liu Z, Zhou X, Wang J, et al. Potential effect of blood purification therapy in reducing cytokine storm as a late complication of critically ill COVID-19. Clinical Immunology (Orlando, Fla). 2020;214:108408.

104. Shi H, Zhou C, He P, Huang S, Duan Y, Wang X, et al. Successful treatment with plasma exchange followed by intravenous immunoglobulin in a critically ill patient with COVID-19. Int J Antimicrob Agents. 2020;56(2):105974.

105. Aminimoghaddam S, Afrooz N, Nasiri S, Motaghi Nejad O, Mahmoudzadeh F. A COVID-19 pregnant patient with thrombotic thrombocytopenic purpura: a case report. J Med Case Rep. 2021;15(1):104.

106. Dogan L, Kaya D, Sarikaya T, Zengin R, Dincer A, Akinci IO, et al. Plasmapheresis treatment in COVID-19-related autoimmune meningoencephalitis: case series. Brain, Behavior, and Immunity. 2020;87:155-8.

107. Gucyetmez B, Atalan HK, Sertdemir I, Cakir U, Telci L. Therapeutic plasma exchange in patients with COVID-19 pneumonia in intensive care unit: a retrospective study. Critical care (London, England). 2020;24(1):492.

108. Honore PM, Mugisha A, Kugener L, Redant S, Attou R, Gallerani A, et al. Therapeutic plasma exchange as a routine therapy in septic shock and as an experimental treatment for COVID-19: we are not sure. Crit Care. 2020;24(1):226.

109. Stahl K, Bode C, David S. First do no harm-beware the risk of therapeutic plasma exchange in severe COVID-19. Crit Care. 2020;24(1):363.

110. Keith P, Day M, Perkins L, Moyer L, Hewitt K, Wells A. A novel treatment approach to the novel coronavirus: an argument for the use of therapeutic plasma exchange for fulminant COVID-19. Crit Care. 2020;24(1):128.

111. Faqihi F, Alharthy A, Alodat M, Asad D, Aletreby W, Kutsogiannis DJ, et al. A pilot study of therapeutic plasma exchange for serious SARS CoV-2 disease (COVID-19): a structured summary of a randomized controlled trial study protocol. Trials. 2020;21(1):506.

112. Ranganathan C, Fusinski SD, Obeid IM, Ismail KM, Ferguson DT, Raminick MF, et al. Therapeutic plasma exchange for persistent encephalopathy associated with Covid-19. eNeurologicalSci. 2021;22:100327.

113. Merigan TC, Reed SE, Hall TS, Tyrrell DA. Inhibition of respiratory virus infection by locally applied interferon. Lancet (London, England). 1973;1(7803):563-7.

114. Hoofnagle JH, Mullen KD, Jones DB, Rustgi V, Di Bisceglie A, Peters M, et al. Treatment of chronic non-A,non-B hepatitis with recombinant human alpha interferon. A preliminary report. The New England journal of medicine. 1986;315(25):1575-8.

115. Aghemo A, Rumi MG, Colombo M. Pegylated interferons alpha2a and alpha2b in the treatment of chronic hepatitis C. Nature Reviews Gastroenterology \& Hepatology. 2010;7(9): 485-94.

116. Lin FC, Young HA. Interferons: success in anti-viral immunotherapy. Cytokine \& Growth Factor Reviews. 2014;25(4):369-76.

117. Randomised double-blind placebo-controlled study of interferon beta-1a in relapsing/remitting multiple sclerosis. PRISMS (Prevention of Relapses and Disability by Interferon beta-1a Subcutaneously in Multiple Sclerosis) Study Group. Lancet (London, England). 1998;352(9139):1498-504.

118. Tenembaum SN, Banwell B, Pohl D, Krupp LB, Boyko A, Meinel $\mathrm{M}$, et al. Subcutaneous interferon Beta-1a in pediatric multiple sclerosis: a retrospective study. Journal of Child Neurology. 2013;28(7):849-56.

119. Kalincik T, Spelman T, Trojano M, Duquette P, Izquierdo G, Grammond $\mathrm{P}$, et al. Persistence on therapy and propensity matched outcome comparison of two subcutaneous interferon beta 1a dosages for multiple sclerosis. PloS one. 2013;8(5):e63480. 
120. Sulkowski MS, Cooper C, Hunyady B, Jia J, Ogurtsov P, PeckRadosavljevic M, et al. Management of adverse effects of Peg-IFN and ribavirin therapy for hepatitis C. Nature Reviews Gastroenterology \& Hepatology. 2011;8(4):212-23.

121. Okanoue T, Sakamoto S, Itoh Y, Minami M, Yasui K, Sakamoto $\mathrm{M}$, et al. Side effects of high-dose interferon therapy for chronic hepatitis C. Journal of Hepatology. 1996;25(3):283-91.

122. Raison CL, Demetrashvili M, Capuron L, Miller AH. Neuropsychiatric adverse effects of interferon-alpha: recognition and management. CNS Drugs. 2005;19(2):105-23.

123. Vallbracht A, Treuner J, Flehmig B, Joester KE, Niethammer D. Interferon-neutralizing antibodies in a patient treated with human fibroblast interferon. Nature. 1981;289(5797):496-7.

124. Dunn N, Fogdell-Hahn A, Hillert J, Spelman T. Long-term consequences of high titer neutralizing antibodies to interferon- $\beta$ in multiple sclerosis. Frontiers in immunology. 2020;11:583560.

125. Aruna LL. Anti-interferon alpha antibodies in patients with highrisk BCR/ABL-negative myeloproliferative neoplasms treated with recombinant human interferon- $\alpha$. Medical Science Monitor. 2018;24:2302-9.

126. Steis RG, Smith JW 2nd, Urba WJ, Clark JW, Itri LM, Evans LM, et al. Resistance to recombinant interferon alfa-2a in hairy-cell leukemia associated with neutralizing anti-interferon antibodies. The New England Journal of Medicine. 1988;318(22):1409-13.

127. Andlauer TFM, Link J, Martin D, Ryner M, Hermanrud C, Grummel V, et al. Treatment- and population-specific genetic risk factors for anti-drug antibodies against interferon-beta: a GWAS. BMC Medicine. 2020;18(1):298.

128. Pellegrini S, Uze G. An old cytokine against a new virus? J Interferon Cytokine Res. 2020;40(8):425-8.

129. Wang N, Zhan Y, Zhu L, Hou Z, Liu F, Song P, et al. Retrospective multicenter cohort study shows early interferon therapy is associated with favorable clinical responses in COVID-19 patients. Cell Host Microbe. 2020;28(3):455-64 e2.

130. Zhou Q, Chen V, Shannon CP, Wei XS, Xiang X, Wang X, et al. Interferon-alpha2b treatment for COVID-19. Front Immunol. 2020;11:1061.

131. Monk PD, Marsden RJ, Tear VJ, Brookes J, Batten TN, Mankowski M, et al. Safety and efficacy of inhaled nebulised interferon beta-1a (SNG001) for treatment of SARS-CoV-2 infection: a randomised, double-blind, placebo-controlled, phase 2 trial. Lancet Respir Med. 2021;9(2):196-206.

132. Hung IF, Lung KC, Tso EY, Liu R, Chung TW, Chu MY, et al. Triple combination of interferon beta-1b, lopinavir-ritonavir, and ribavirin in the treatment of patients admitted to hospital with COVID-19: an open-label, randomised, phase 2 trial. Lancet. 2020;395(10238):1695-704.

133. Davoudi-Monfared E, Rahmani H, Khalili H, Hajiabdolbaghi M, Salehi M, Abbasian L, et al. A randomized clinical trial of the efficacy and safety of interferon beta-1a in treatment of severe COVID-19. Antimicrob Agents Chemother. 2020;64(9).

134. Rahmani H, Davoudi-Monfared E, Nourian A, Khalili H, Hajizadeh N, Jalalabadi NZ, et al. Interferon beta- $1 \mathrm{~b}$ in treatment of severe COVID-19: a randomized clinical trial. Int Immunopharmacol. 2020;88:106903.

135. Dastan F, Nadji SA, Saffaei A, Marjani M, Moniri A, Jamaati H, et al. Subcutaneous administration of interferon beta-1a for COVID-19: a non-controlled prospective trial. Int Immunopharmacol. 2020;85:106688.

136. Mary A, Henaut L, Macq PY, Badoux L, Cappe A, Poree T, et al. Rationale for COVID-19 treatment by nebulized interferon-beta$1 \mathrm{~b}$-literature review and personal preliminary experience. Front Pharmacol. 2020;11:592543.

137. Hong SI, Ryu BH, Chong YP, Lee S, Kim S, Kim HC, et al. Five severe COVID-19 pneumonia patients treated with triple combination therapy with lopinavir/ritonavir, hydroxychloroquine, and interferon beta-1b. Int J Antimicrob Agents. 2020;56(2):106052.

138. Angus DC, Derde L, Al-Beidh F, Annane D, Arabi Y, Beane A, et al. Effect of hydrocortisone on mortality and organ support in patients with severe COVID-19: the REMAP-CAP COVID-19 Corticosteroid Domain Randomized Clinical Trial. Jama. 2020;324(13):1317-29.

139. Bosi E, Bosi C, Rovere Querini P, Mancini N, Calori G, Ruggeri A, et al. Interferon beta-1a (IFNbeta-1a) in COVID-19 patients (INTERCOP): study protocol for a randomized controlled trial. Trials. 2020;21(1):939.

140. Alavi Darazam I, Hatami F, Rabiei MM, Pourhoseingholi MA, Moradi O, Shokouhi S, et al. An investigation into the beneficial effects of high-dose interferon beta 1-a, compared to low-dose interferon beta $1-\mathrm{a}$ (the base therapeutic regimen) in moderate to severe COVID-19: A structured summary of a study protocol for a randomized controlled 1 trial. Trials. 2020;21(1):880.

141. Hart BJ, Dyall J, Postnikova E, Zhou H, Kindrachuk J, Johnson RF, et al. Interferon-beta and mycophenolic acid are potent inhibitors of Middle East respiratory syndrome coronavirus in cellbased assays. The Journal of General Virology. 2014;95(Pt 3): $571-7$.

142. Cinatl J, Morgenstern B, Bauer G, Chandra P, Rabenau H, Doerr HW. Treatment of SARS with human interferons. Lancet. 2003;362(9380):293-4.

143. Mantlo E, Bukreyeva N, Maruyama J, Paessler S, Huang C. Antiviral activities of type I interferons to SARS-CoV-2 infection. Antiviral Res. 2020;179:104811.

144. Arabi YM, Asiri AY, Assiri AM, Balkhy HH, Al Bshabshe A, Al Jeraisy $\mathrm{M}$, et al. Interferon beta- $1 \mathrm{~b}$ and lopinavir-ritonavir for Middle East respiratory syndrome. N Engl J Med. 2020;383(17): 1645-56.

145. Khamis F, Al Naabi H, Al Lawati A, Ambusaidi Z, Al Sharji M, Al Barwani U, et al. Randomized controlled open label trial on the use of favipiravir combined with inhaled interferon beta-1b in hospitalized patients with moderate to severe COVID-19 pneumonia. Int J Infect Dis. 2021;102:538-43.

146. To KK, Tsang OT, Leung WS, Tam AR, Wu TC, Lung DC, et al. Temporal profiles of viral load in posterior oropharyngeal saliva samples and serum antibody responses during infection by SARSCoV-2: an observational cohort study. Lancet Infect Dis. 2020;20(5):565-74.

147. Hillyer P, Mane VP, Schramm LM, Puig M, Verthelyi D, Chen A, et al. Expression profiles of human interferon-alpha and interferon-lambda subtypes are ligand- and cell-dependent. Immunology and Cell Biology. 2012;90(8):774-83.

148. Crotta S, Davidson S, Mahlakoiv T, Desmet CJ, Buckwalter MR, Albert ML, et al. Type I and type III interferons drive redundant amplification loops to induce a transcriptional signature in influenza-infected airway epithelia. PLoS Pathogens. 2013;9(11):e1003773.

149. Vanderheiden A, Ralfs P, Chirkova T, Upadhyay AA, Zimmerman MG, Bedoya S, et al. Type I and type III interferons restrict SARS-CoV-2 infection of human airway epithelial cultures. Journal of Virology. 2020;94(19).

150. Dinnon KH 3rd, Leist SR, Schäfer A, Edwards CE, Martinez DR, Montgomery SA, et al. A mouse-adapted model of SARS-CoV-2 to test COVID-19 countermeasures. Nature. 2020;586(7830): $560-6$.

151. Feld JJ, Kandel C, Biondi MJ, Kozak RA, Zahoor MA, Lemieux $\mathrm{C}$, et al. Peginterferon lambda for the treatment of outpatients with COVID-19: a phase 2, placebo-controlled randomised trial. Lancet Respiratory Med.

152. Jagannathan P, Andrews JR, Bonilla H, Hedlin H, Jacobson KB, Balasubramanian V, et al. Peginterferon lambda-1a for treatment 
of outpatients with uncomplicated COVID-19: a randomized placebo-controlled trial. Nat Commun. 2021;12(1):1967.

153. Major J, Crotta S, Llorian M, McCabe TM, Gad HH, Priestnall SL, et al. Type I and III interferons disrupt lung epithelial repair during recovery from viral infection. Science. 2020;369(6504): $712-7$.
154. Broggi A, Ghosh S, Sposito B, Spreafico R, Balzarini F, Lo Cascio A, et al. Type III interferons disrupt the lung epithelial barrier upon viral recognition. Science. 2020;369(6504):706-12.

Publisher's Note Springer Nature remains neutral with regard to jurisdictional claims in published maps and institutional affiliations. 